\section{TECHNISCHE} UNIVERSITÄT

WIEN

Vienna University of Technology

D I P L O M A R B E I T

\title{
CHARACTERIZING COARSE-SCALE REPRESENTATIVENESS OF IN-SITU SOIL MOISTURE MEASUREMENTS FROM THE INTERNATIONAL SOIL Moisture NeTWORK
}

Ausgeführt am Department für Geodäsie und Geoinformation der Technischen Universität Wien

unter der Anleitung von

Univ.Prof. Dipl.-Ing. Dr.techn. Wolfgang Wagner

und der Betreuung durch

MSc. Dr.rer.nat. Wouter Dorigo

durch

Alexander Gruber

Babenbergergasse $7 / 4 / 3$

2340 Mödling 


\section{Abstract}

In-situ soil moisture measurements play a key role for a variety of large-scale applications. A deep understanding of their quality, especially in terms of spatial representativeness, is crucial for reliably using them as reference data. This study assesses random errors in the coarse-scale representation of in-situ soil moisture measurements from more than 1400 globally distributed stations in the International Soil Moisture Network (ISMN) using the triple collocation method. The method was applied on the original measurements as well as on soil moisture anomalies. Error estimates were summarized for different networks, depths, and measurement principles and furthermore related to the respective climate class, soil type, average soil moisture condition, and soil moisture variability to find possible relationships between measurement errors and local properties. The average network error varies from about 0.02 to $0.06 \mathrm{~m}^{3} \mathrm{~m}^{-3}$ with generally increasing error variability with increasing average error. Trends of (i) decreasing errors with increasing measurement depth and of (ii) increasing errors with increasing average soil moisture conditions and soil moisture variability were found for most networks and sensor types. The errors when looking into anomalies are in general lower than for absolute values. No statistically reliable trends for climate- and soil texture classes were found. The results highlight the necessity of developing a comprehensive quality control process for in-situ measurements to reliably exploit existing data sets and to select representative sites and sensors most appropriate for the requirements of a particular larger-scale application. 


\section{Kurzfassung}

In-situ Bodenfeuchtemessungen spielen eine Schlüsselrolle für viele groß-maßstäbige Anwendungen. Ein tiefgehendes Verständniss ihrer Qualität, vor allem bezogen auf ihre räumliche Repräsentativität ist essentiell um sie als Referenzdaten verwenden zu können. Diese Studie befasst sich mit der Schätzung zufälliger Fehler in der grob-maßstäbigen Representation von in-situ Bodenfeuchtemessungen von über 1400 global verteilten Stationen des International Soil Moisture Network (ISMN) unter der Verwendung der Triple Collocation Methode. Die Methode wurde sowohl auf die absoluten Messwerte als auch auf Bodenfeuchteanomalien angewendet. Die Fehler wurden für verschiedene Netzwerke, Messtiefen und Sensortypen zusammengefasst und mit Klimaklassen, Bodentypen und Feuchtebedingungen in Verbindung gebracht. Der durchschnittliche Messfehler pro Netzwerk variiert zwischen 0.02 to $0.06 \mathrm{~m}^{3} \mathrm{~m}^{-3}$, mit einer Tendenz zu steigender Fehlervariabilität mit steigendem mittleren Fehler. Trends für (i) geringere Fehler für größere Messtiefen und (ii) steigende Fehler für steigende mittlere Bodenfeuchte und -variabilität wurden für die meisten Netzwerke und Sensortypen gefunden. Fehler in den Anomalien waren im Durchschnitt geringer als Fehler der Absolutwerte. Es gab keinen statistisch vertrauenswürdigen Zusammenhang zwischen Fehlern und Klimaklassen bzw. Bodentypen. Diese Ergebnisse zeigen die Wichtigkeit der Entwicklung einer umfassenden Qualitätskontrollmethodik für in-situ Messungen, damit bestehende Datensätze zuverlässig verwendet und representative Stationen bzw. Sensoren zur Verwendung in einer groß-maßstäbigen Anwendung ausgewählt werden können 


\section{Acknowledgments}

I thank my supervisors Wouter Dorigo and Wolfgang Wagner for their great support and for giving me the scientific freedom that made this thesis and the journal paper on which it is based (Gruber et al., 2013) possible.

I furthermore greatly thank all data providers that kindly shared their data with the ISMN: Jeffrey Walker (AACES; http://www.moisturemap.monash.edu.au), Thierry Pellarin (AMMA; http://amma-international.org), Jim Mather (ARM; http://www.arm.gov), Loredana Marsica and Luca Brocca (CALABRIA; http://www.cfcalabria.it), Matteo Gentilella and Giovanni Battista Chirico (CAMPANIA; http://www.regione.campania.it), Konstantin Vinnikov and Thomas Collow (CHINA, IOWA,MONGOLIA, RUSWET-AGRO, RUSWET-GRASS, and RUSWET-VALDAI; Robock et al., 20oo), Marek Zreda (COSMOS; http://cosmos.hwr.arizona.edu), Dennis D. Baldocchi (FLUXNET-AMERIFLUX; http://www.fluxnet.ornl.gov/fluxnet/index.cfm), Matias Takala, Hanne Suokanerva, Jouni Pullianen, Jarkko Koskinen (FMI; http://fmiarc.fmi.fi), Alessia Flammini and Renato Morbidelli (HYDROL-NET_PERUGIA; http://www.dica.unipg.it/DICA), Simone Bircher (HOBE; http://www.hobe.dk), Minha Choi and Yeon Gil Lee (HYU_CHEONGMICHEON; http://wrrsl.hanyang.ac.kr/html/introduction.htm, HSC_SELMACHEON; http://www.hsc.re.kr), Bob Scott (ICN; http://www.isws.illinois.edu/warm), Pankaj Kumar Rai and Shivam Tripathi (ITT_KANPUR; http://www.iitk.ac.in), Laura Dente, Bob Su, and J. Wen (MAQU; Su et al., 2011), Nazzareno Diodato (MetEROBS; http://mistrals.sedoo.fr/HyMeX/Plateform-search?datsId=532), Udo Rummel (MOL-RAO; http://www.dwd.de/mol), Jeffrey Walker and Christoph Rüdiger (OZNET; http://www.oznet.org.au), José Martínez Fernández (REMEDHUS; http://campus . usal . es/ hidrus), Garry Schaeffer, Michael Strobel, Maggie Dunklie, Michael Cosh, and Robert Parry (SCAN; http://www.wcc.nrcs.usda.gov/scan), Jean-Christophe Calvet (SMOSMANIA; http : / /www . hymex . org), Michael Strobel and Garry Schaeffer (SNOTEL; http://www.wcc.nrcs.usda.gov/snow), Boguslaw Usowicz, Jerzy Usowicz, and Wojciech Marczewski (SWEX_Poland; Marczewski et al., 2010), Florian Schlenz, Johanna dall'Amico, Alexander Loew, Wolfram Mauser (UDC_SMOS; http://www.geographie.uni-muenchen . de/department/fiona/forschung/projekte/index.php?projekt_id=103), Luca Brocca and Nicola Berni (UMBRIA; http://www.cfumbria.it), Vittorio Marletto and Marco Bittelli (UMSUOL; Brocca et al., 2011), Michael Palecki (USCRN; http://www.ncdc.noaa.gov/crn), 
Michael Cosh and Thomas Jackson (USDA-ARS; Jackson et al., 2010). Without their valuable contributions this initiative would not have been possible in the first place. The ISMN has been funded through the SMOS Soil Moisture Network Study (ESA ESTEC Contract No.22954/o9) and the SMOS Soil Moisture Network Study - Operational Phase (ESA ESTEC Contract No.4000102722/10). 


\section{Contents}

List of Acronyms $\quad$ xi

List of Figures $\quad$ xii

List of Tables $\quad$ xiv

1 Introduction 1

2 Theoretical background $\mathbf{5}$

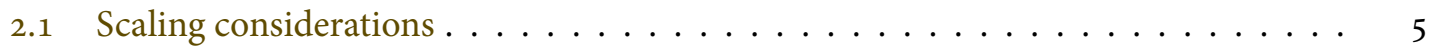

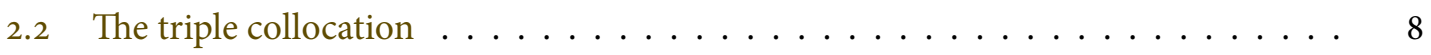

$2.2 .1 \quad$ Mathematical model . . . . . . . . . . . . . . . . . 8

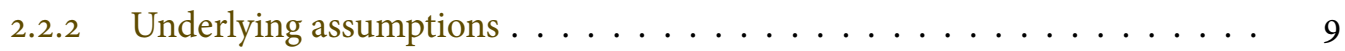

2.2 .3 Impact of random scaling errors $\ldots \ldots \ldots \ldots \ldots \ldots \ldots$

3 Data Sets 13

3.1 In-situ soil moisture measurements . . . . . . . . . . . . . . . 13

3.2 Remotely Sensed Soil Moisture . . . . . . . . . . . . . . . . . . . . . 17

3.3 Modelled soil moisture . . . . . . . . . . . . . . . . . . . . . . . 17

3.4 Koeppen-Geiger Climate Classification . . . . . . . . . . . . . . . . . . . 17

3.5 Harmonized World Soil Database . . . . . . . . . . . . . . . . . . 18

4 Methodology 19

4.1 Implementation of the Triple Collocation . . . . . . . . . . . . . . . . . . 19

4.1.1 Rescaling of original estimates . . . . . . . . . . . . . . . . . 19

4.1.2 Anomalies . . . . . . . . . . . . . . . . . . . 20

4.1 .3 Spatial and temporal collocation ............... 20

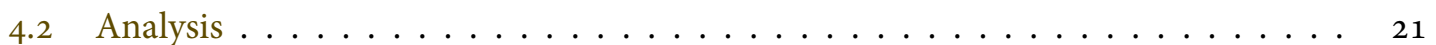

4.2.1 Sensor quality on a network, depth and sensor type level . . . . . . . 21

4.2.2 Climate class analysis . . . . . . . . . . . . . . . . 21

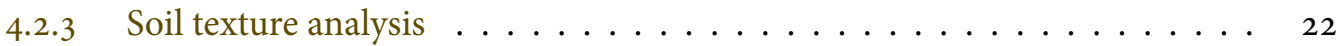

5 Results and Discussion $\quad 25$ 


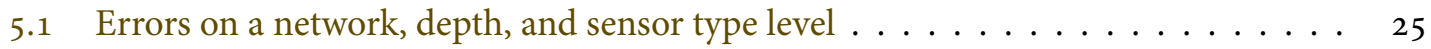

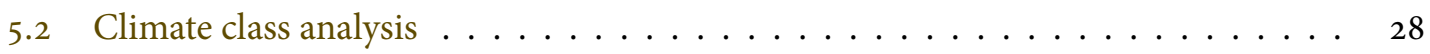

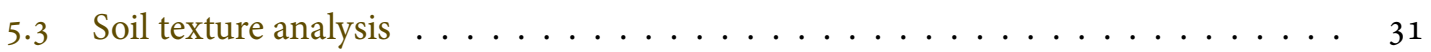

6 Conclusion and Outlook 33

$\begin{array}{ll}\text { Bibliography } & 35\end{array}$ 


\section{List of Acronyms}

$\begin{array}{ll}\text { CCI } & \text { Climate Change Initiative } \\ \text { CDF } & \text { Cumulative Distribution Function } \\ \text { ECMWF } & \text { European Center for Medium-range Weather Forecasts } \\ \text { ERA } & \text { ECMWF ReAnalysis } \\ \text { ESA } & \text { European Space Agency } \\ \text { FDR } & \text { Frequency Domain Reflectometry } \\ \text { HTESSEL } & \text { Revised land surface Hydrology TESSEL } \\ \text { HWSD } & \text { Harmonized World Soil Database } \\ \text { IQR } & \text { Inter-Quartile-Range } \\ \text { ISMN } & \text { International Soil Moisture Network } \\ \text { MSD } & \text { Mean-Square-Difference } \\ \text { NRT } & \text { Near Real Time } \\ \text { RMSD } & \text { Root Mean Square Difference } \\ \text { SMAP } & \text { Soil Moisture Active Passive } \\ \text { SMOS } & \text { Soil Moisture and Ocean Salinity } \\ \text { TDR } & \text { Time Domain Reflectometry } \\ \text { TESSEL } & \text { Tiled ECMWF Scheme for Surface Exchanges over Land } \\ \text { USDA } & \text { United States Department of Agriculture } \\ \text { WACMOS } & \text { WAter Cycle Multi-mission Observation Strategy }\end{array}$




\section{List of Figures}

2.1 Spatial station distribution of the ISMN . . . . . . . . . . . . 6

2.2 Dependency of the triple collocation on the number of triplets . . . . . . . . 11

2.3 Estimated against actual representativeness errors . . . . . . . . . . . . 12

3.1 Spatial station distribution of the ISMN . . . . . . . . . . . . . . 14

3.2 Temporal data coverage . . . . . . . . . . . . . . . . 15

4.1 Climate class distribution . . . . . . . . . . . . . . . . . 21

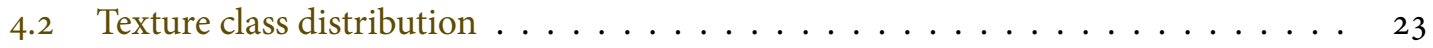

5.1 Errors on a network level . . . . . . . . . . . . . . . 26

5.2 Errors on a sensor type level . . . . . . . . . . . . . . . . . 27

5.3 Absolute and anomaly errors . . . . . . . . . . . . . . . . 28

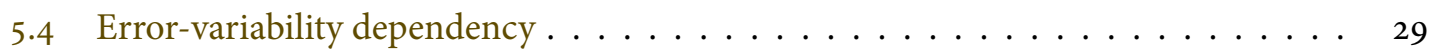

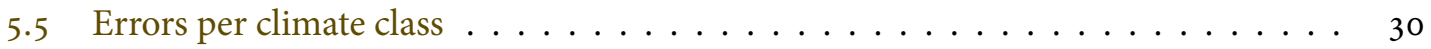

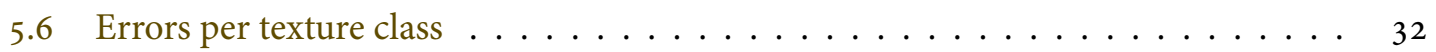




\section{List of Tables}

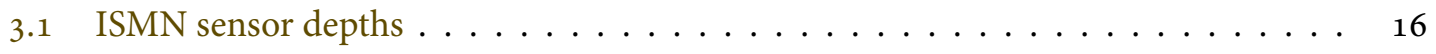

4.1 Koeppen-Geiger classes . . . . . . . . . . . . . . . . . . 22

4.2 Texture classes . . . . . . . . . . . . . . . . . . 24 



\section{Chapter 1}

\section{Introduction}

This thesis is based on the journal paper "Characterizing Coarse-Scale Representativeness of in situ Soil Moisture Measurements from the International Soil Moisture Network" (Gruber et al., 2013) and extends it with the theoretical background about the physical phenomena occurring in an up-scaling process and its impact on the triple collocation.

A large number of local- to regional-scale meteorological and experimental networks measuring soil moisture in-situ is available worldwide. Nevertheless, soil moisture is highly variable in space and time and a globally representative in-situ network would require an extremely large number of stations. The high costs for operation and maintenance, together with the limited accessibility of certain regions, make the setup of such an in-situ network financially infeasible. To fill this gap, remotely sensed data from optical and microwave instruments has been used to retrieve soil moisture on a global scale (Chauhan et al., 2003; Njoku et al., 2003; Wagner et al., 1999). Several missions such as the Soil Moisture and Ocean Salinity mission (SMOS; Kerr et al., 2010) or the Soil Moisture Active Passive (SMAP; Entekhabi et al., 2010), especially dedicated to estimate soil moisture with footprint sizes of several kilometers, have been launched recently or will be launched in the near future. Satellite sensors provide data with a maximum temporal resolution of 1 to 3 days, which is not sufficient for a large variety of applications. Land surface models have been implemented to fill this temporal gap providing data in about the same spatial resolution of meters to kilometers but several times a day.

Nevertheless, ground-based measurements are still crucial not only for studying the spatial and temporal dynamics of soil moisture on a local scale (Brocca et al., 2010a, 2007, 2012; Mittelbach et al., 2011; Robinson et al., 2008; Vereecken et al., 2010), but also for the calibration and validation of coarse-scale data sets (Albergel et al., 2012; Parrens et al., 2011). In this context, in-situ data sets are often seen as ground "truth," which in fact is an inappropriate term since (i) in-situ sensors and their deployment underlie inherent errors (Mittelbach et al., 2012; Plauborg et al., 2005; Walker et al., 2004) and (ii) differences in the spatial scale, the represented depth, and the underlying physical measurement principles of the sensors introduce systematic differences between the represented 
extent of the observation as well as the actual represented physical quantity (Brocca et al., 2007; Famiglietti et al., 1999, 2008; Miralles et al., 2010). In-situ sensors typically represent only a few centimeters of the soil and are usually placed in depths between the surface and 1 to $2 \mathrm{~m}$ to represent the plant root zone, whereas the penetration depth of satellite signals is about the size of the wavelength, i.e., about o to $5 \mathrm{~cm}$ (Schmugge, 1983), covering an area from several square-meters to several thousand square-kilometers. Vegetation coverage, topography, soil type, spatial weather variability, and many other factors introduce subfootprint-scale soil moisture variations that may cause differences between shallow spatial average surface soil moisture estimates from satellites or models and in-situ measurements, depending on where the in-situ sensor is located within the footprint. In fact, satellite and in-situ sensors will never look into the same soil sample and hence do not measure the same water volume.

Nevertheless, Vachaud et al. (1985) introduced the temporal stability concept for soil moisture, stating that even though soil moisture is highly variable in space and time, spatial fields of soil moisture exist, which persist in time. Single stations within those fields can be used to represent the areal mean soil moisture behavior over larger areas. Based on this temporal stability concept, many other studies investigated the spatio-temporal variability of soil moisture over a large range of scales to assess the feasibility of using point-scale in-situ measurements as a representation also for larger-scale average soil moisture (Brocca et al., 2010a, 2007, 2012; Cosh et al., 2006; Famiglietti et al., 1999, 2008; Martinez-Fernandez and Ceballos, 2003, 2005). The main findings of these studies were that (i) a limited number of sites distributed over an area of interest can be used to reliably represent its average soil moisture behavior, (ii) the number of sites required to obtain a certain quality within a given confidence depends on the scale difference and the soil moisture conditions since spatiotemporal variability increases with increasing scale and reaches a maximum under intermediate wetness conditions, and (iii) almost all stations follow the temporal behavior of the areal mean in terms of the correlation whereas only few stations are able to represent the areal mean absolute soil moisture level. Differences in the latter mainly result from variations in vegetation, topography, soil texture, and climate, and are often of a systematic nature. Hence, appropriate scaling techniques can be used to remove such differences (Crow et al., 2012; Famiglietti et al., 2008; Kumar et al., 2012; Reichle and Koster, 2004). Single point-scale in-situ measurements might then be properly used as a reference for coarse-scale mean soil moisture (Albergel et al., 2012; Jackson et al., 2010). Further studies investigated also the temporal stability of soil moisture in depth, indicating a correlation of soil moisture along the soil profile (Martinez-Fernandez and Ceballos, 2003; Pachepsky et al., 2005; Starks et al., 2006). In fact, Wagner et al. (1999) developed a method to estimate coarse-scale profile soil moisture using surface soil moisture estimates from satellites. Various studies verified the usefulness of this method by comparing the estimated profile soil moisture to in-situ measurements in depth (Albergel et al., 2009, 2008; Brocca et al., 2010b). Their results proved an existing correlation for soil moisture along the profile.

Nevertheless, no single station can be entirely representative for larger areas or the entire 
profile range because of the heterogeneity in soil properties, topography, and weather behavior. Nonsystematic differences caused by the limited spatial representativeness of single points (referred to as scaling errors) are preserved and must be considered when comparing soil moisture data sets across scales (Crow et al., 2012; Miralles et al., 2010). Beside those systematic differences and random errors, every in-situ sensor underlies inherent errors such as sensor noise, miscalibration, or a bad deployment.

From the previous it becomes clear that the use of in-situ measurements for evaluating satellite or modelled data requires a detailed knowledge of their quality. One should be aware that the term quality for in-situ data describes several properties, whose importance varies with the application. Four different properties should be distinguished: (i) the capability of an in-situ sensor to measure absolute soil moisture levels, (ii) the capability of capturing the temporal dynamics (drying and wetting events), (iii) the spatial representativeness of a single station for a certain area, and (iv) the inherent sensor reliability (e.g., the probability for sensor-dropouts or outliers, sensor drifts, or random noise). Different approaches are available for assessing one or more of these properties. Common metrics are the correlation coefficient, which assesses the temporal relationship between two data sets, and the bias and Root-Mean-Square-Difference (RMSD) for quantifying relative measurement differences. Those metrics can be applied on the soil moisture measurements directly or on soil moisture anomalies, which are usually defined as the difference between actual measurements and a long-term climatology (Albergel et al., 2012; Dorigo et al., 2010). Looking into the direct measurements addresses the sensor's capability of measuring absolute soil moisture levels, whereas anomalies can be used to assess the capability for capturing drying and wetting events. Using a high spatial sensor density allows the assessment of the spatial representativeness of in-situ sensors when comparing the respective measurements with the areal average. All the mentioned metrics require reliable reference data sets, which are usually manually collected gravimetric samples or high quality sensor measurements taken under laboratory conditions with prepared soil samples or under field conditions (Mittelbach et al., 2012; Cataldo et al., 2009; Plauborg et al., 2005).

A new approach of assessing the occurrence of measurement outliers without the need of any reference data was introduced by Dorigo et al. (2013), who used spectrum-based analysis to find and flag spikes, jumps, saturated responses, missing precipitation responses, and sensor drop-outs. One possible method for quantifying measurement errors without relying on the quality of reference data sets might be the so-called triple collocation method. This is a method for estimating the random errors of three collocated data sets which can be assumed to represent the same physical parameter while simultaneously solving for systematic differences. The method assumes independent (uncorrelated) error structures, which means that the errors must not have the same origin. This is given when using e.g., any combination of in-situ measurements, active or passive satellite observations, and land surface model estimates, provided that the model is not driven by one of the others. Several studies highlighted the high potential of the triple collocation in 
becoming a standard procedure in a comprehensive satellite validation process (Dorigo et al., 2010; Miralles et al., 2010; Scipal et al., 2008; Stoffelen, 1998). Nevertheless, studies also showed that the result is highly sensitive to its input configuration, including different scales and represented physical quantities of the sources, the use of absolute values or anomalies, the time span under observation, and the available number of measurement triplets (Loew and Schlenz, 2011; Zwieback et al., 2012, 2013). As mentioned, large-scale differences between the input data sets introduce errors caused by the spatio-temporal variability of soil moisture, leading to a mismatch in the spatial representativeness. These errors are reflected in the triple collocation result and can take a high fraction of the overall error, leading to an overestimation of the actual inherent sensor error (Miralles et al., 2010). The only way to remove these scaling errors is the assessment of the spatial representativeness, which requires a high spatial sensor density. Unfortunately, only few available in-situ networks provide such a density. The main objective of this study is to use the triple collocation to characterize the random errors of globally available in-situ measurements in their purpose of representing footprint-scale $\left(\sim 0.25^{\circ}\right)$ soil moisture. It should be emphasized that, in the context of this study, the term random error describes not only the inherent random sensor noise but also the non-systematic part in the scaling process, caused by the spatio-temporal variability of soil moisture (i.e., the scaling error), which is most likely dominating the overall error estimate. A second objective of this study is to investigate possible relationships between random error levels and site-specific properties which are expected to have a large impact on in-situ measurements or soil moisture variability. These properties are (i) sensor types, (ii) observation depths, (iii) climate regions, and (iv) soil types. The data sets used for this study are drawn from the International Soil Moisture Network (ISMN). 


\section{Chapter 2}

\section{Theoretical background}

\subsection{Scaling considerations}

As described in Chapter 1, systematic and random differences are introduced by the different geophysical phenomena affecting spatio-temporal soil moisture variability at different scales, i.e., soil properties, topography, vegetation and weather variability (Figure 2.1). The question arises how these systematic and random differences, referred to as scaling errors, add to actual measurement errors and how and if they can be separated from the latter in a validation process. In the following, these questions will be discussed on the example of in-situ measurements that should be upscaled to match the spatial scale of satellite measurements (in the following referred to as field scale).

Estimates of the true state of soil moisture at the respective scale are derived by applying an empirical or analytical model on the actual sensor readings. The model describes the relationship between the observed sensor quantity and soil moisture:

$$
\begin{aligned}
& \hat{\Theta}_{\text {point }}=\hat{F}_{\text {insitu }}(\hat{U})=F_{\text {insitu }}\left(\Theta_{\text {point }}\right)+\varepsilon_{\text {insitu }} \\
& \hat{\Theta}_{\text {field }}=\hat{F}_{\text {satellite }}\left(\hat{\sigma}_{0} / \hat{T}_{b}\right)=F_{\text {satellite }}\left(\Theta_{\text {field }}\right)+\varepsilon_{\text {satellite }}
\end{aligned}
$$

$\Theta_{\text {point }}$ and $\Theta_{\text {field }}$ are the true states of point-scale and field-scale soil moisture, $\hat{\Theta}_{\text {point }}$ and $\hat{\Theta}_{\text {field }}$ their respective in-situ and satellite based measurements. $\hat{F}_{\text {insitu }}$ and $\hat{F}_{\text {satellite }}$ are the models applied on the actual measured sensor raw data (e.g., the voltage $\hat{U}$ from the in-situ sensor or backscatter $\hat{\sigma}_{0}$ or brightness temperature $\hat{T}_{b}$ from the satellite antenna) to derive the respective soil moisture states. The imperfectness of every model and the fact that the sensor observes not soil moisture itself but a quantity related to it introduces systematic and random errors in the estimates of the "truth". $F_{\text {insitu/satellite }}\left(\Theta_{\text {point } / \text { field }}\right)$ and $\varepsilon_{\text {insitu/satellite }}$ express the true relationship (including systematic and random errors) between the soil moisture estimates at the respective scales and the true values. The hats always refer to estimated or measured quantities.

Since soil moisture at the point scale and at the field scale are physically two different water volumes with only a small intersection one must take their systematic difference (e.g., a rainfall event that 


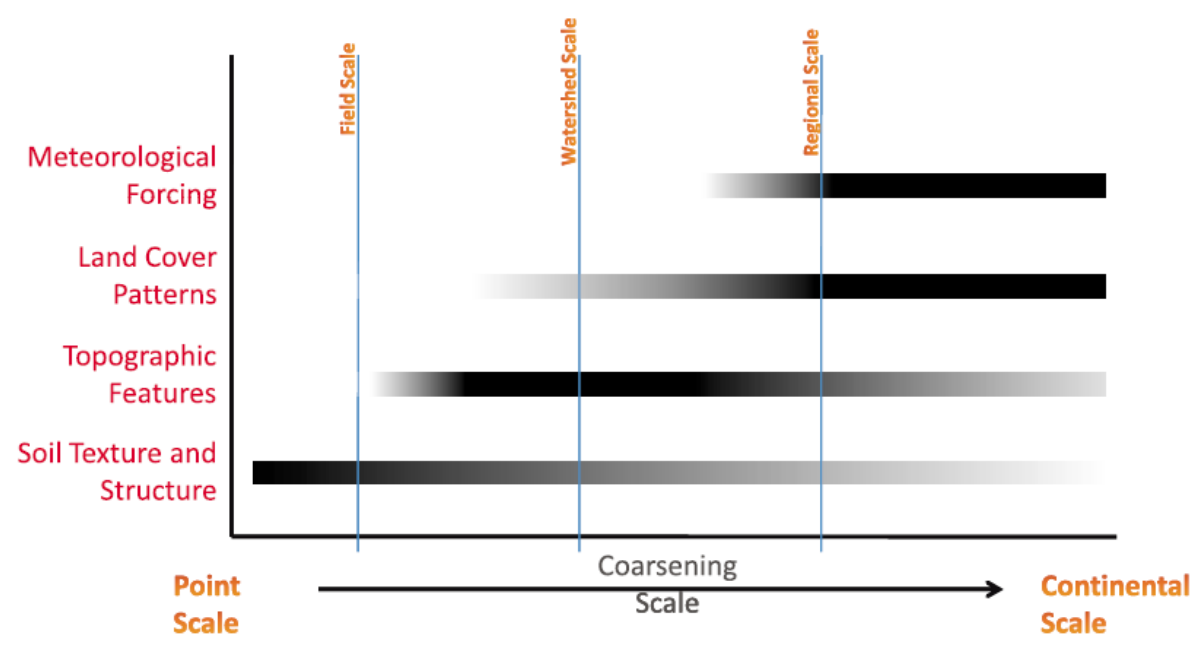

Figure 2.1: Sources of spatio-temporal soil moisture variability at different scales (Crow et al., 2012).

affects the entire point, but only a small area of the field) and the random differences caused by the limited spatial representativeness (e.g., a rainfall event in the field that does not cover the point) into account when comparing estimates of both against each other.

The true scaling parameters will always remain, like every true state of any geophysical parameter, unknown. Nevertheless, as mentioned in Chapter 1, an upscaling function can be statistically derived and applied on the point measurements to minimize systematic differences between the point-scale and the field-scale soil moisture estimates. However, this scaling function will be just an approximation of the true scaling parameters and will thus introduce additional error terms:

$$
\begin{aligned}
\Theta_{\text {field }} & =F_{\uparrow}\left(\Theta_{\text {point }}\right)+\varepsilon_{s} \\
\Theta_{\text {point }} & =F_{\downarrow}\left(\Theta_{\text {field }}\right)+\varepsilon_{s} \\
\hat{F}_{\uparrow}\left(\Theta_{\text {point }}\right) & =F_{\uparrow}^{*}\left(\Theta_{\text {field }}\right)+\varepsilon_{s}+\varepsilon_{s, \hat{F}_{\uparrow}}
\end{aligned}
$$

$F_{\uparrow}$ and $F_{\downarrow}$ refer to the true up- and downscaling functions, respectively, $\varepsilon_{s}$ to the true upscaling error (i.e., representativeness error), $\hat{F}_{\uparrow}$ to the derived upscaling function, and $F_{\uparrow}^{*}$ and $\varepsilon_{s, \hat{F}_{\uparrow}}$ to the systematic and random errors introduced when applying the estimated scaling function on the true point-scale soil moisture to estimate true field-scale soil moisture. Since the true soil moisture state at the point is unknown the estimated function has to be applied on the point-scale estimates measured in-situ:

$$
\begin{aligned}
\hat{\Theta}_{\text {field }, u p} & =\hat{F}_{\uparrow}\left(\hat{\Theta}_{\text {point }}\right)=\hat{F}_{\uparrow}\left(F_{\text {insitu }}\left(\Theta_{\text {point }}\right)+\varepsilon_{\text {insitu }}\right) \\
& =\hat{F}_{\uparrow}\left(F_{\text {insitu }}\left(F_{\downarrow}\left(\Theta_{\text {field }}\right)+\varepsilon_{\text {insitu }}\right)\right)+\varepsilon_{s}+\varepsilon_{s, \hat{F}_{\uparrow}}
\end{aligned}
$$

That is, the upscaled point measurements contain 5 errors with respect to the true field-scale soil moisture: 
- the true systematic scaling error minimized through the estimated scaling function, i.e. the systematic deviation of the derived-from the true scaling function $\left(\hat{F}_{\uparrow}\left(F_{\downarrow}\left(\Theta_{\text {field }}\right)\right)\right.$

- the upscaled systematic deviation of the point measurement from the true point-scale soil moisture state $\left(\hat{F}_{\uparrow}\left(F_{\text {insitu }}\left(\Theta_{\text {point }}\right)\right)\right)$

- the true random scaling error $\left(\varepsilon_{s}\right)$

- an additionally introduced random error caused by the imperfectness of the derived scaling function $\left(\varepsilon_{s, \hat{F}_{\uparrow}}\right)$

- the upscaled true random in-situ measurement error of the point measurement $\left(\hat{F}_{\uparrow}\left(\varepsilon_{\text {insitu }}\right)\right)$

It is common practice that upscaled in-situ measurements are used for validating field-scale satellite observations. Under the assumption that errors of in-situ sensors are significantly lower than errors of the satellite, point measurements are often used as a reference to describe systematic and random errors of the field-scale soil moisture estimates, i.e., the satellite measurements (e.g., through the RMSD and/or the bias). From the previous it is clear that such an approach is unlikely valid since (i) scaling errors are introduced in the upscaling process and (ii) this upscaling process also inflates the actual in-situ sensor errors. It should be emphasized that this study addresses large-scale applications and not applications in which satellites should derive point-scale soil moisture.

The remaining questions are: (i) How big are the scaling errors compared to actual sensor errors, (ii) is it possible to separate these two types of errors, and (iii) can point-scale measurements be used for validating field-scale satellite observations given considerable scaling errors.

The separation of scaling and sensor errors is only possible when having both a good approximation of the actual sensor error and a good approximation of large-scale field soil moisture. First can be achieved with a good accuracy using field- and/or laboratory calibrations (Mittelbach et al., 2012). Second is a very challenging task given the huge size of satellite footprints and the high spatio-temporal dynamics of soil moisture (e.g., Brocca et al., 2007, 2010a, 2012). Unfortunately, only few high-density networks capable of approximating true field-scale soil moisture exist worldwide (see Chapter 3.1).

This study aims to estimate the coarse-scale representativeness of in-situ sensors on a global scale. The term representativeness refers to both upscaling errors themselves and the upscaled in-situ measurement errors, since these are, as described above, inseparable for in-situ networks with a low spatial station density. In the following section, the triple collocation method will be introduced as a method capable of estimating the random errors of in-situ networks with respect to a coarser scale, i.e. their spatial representativeness, without relying on a error-free reference data set. 


\subsection{The triple collocation}

\subsubsection{Mathematical model}

This chapter addresses the issue of using upscaled in-situ soil moisture measurements for validating satellite observations. Therefore the Mean-Square-Difference (MSD) will be introduced first and then extended to the triple collocation.

As described in Section 2.1, the upscaling process corrects for systematic scaling errors with a remaining part due to the unknown true relationship between soil moisture at the respective scales. However, for this study we assume the statistical relationship to be sufficiently described by the methods described in Chapter 4.1. However, deviations from this assumption will lead to an overestimation of the random up-scaling errors, i.e., the representativeness errors. An estimation of the impact on this effect requires further research but is not part of this study.

Given the previously described assumption the upscaled in-situ measurements can be expressed in the following way:

$$
\hat{\Theta}_{i n s}^{*}=\Theta_{f i e l d}+\varepsilon_{i n s}^{*}
$$

$\hat{\Theta}_{i n s}^{*}$ refers to upscaled in-situ measurements, $\Theta_{\text {field }}$ to the true soil moisture at field scale, and $\varepsilon_{i n s}^{*}$ to the upscaling error plus the upscaled sensor error. Assuming further that systematic model errors of the satellite retrieval are negligible, one can describe its relation to the true field-scale soil moisture as the following:

$$
\hat{\Theta}_{\text {sat }}=\Theta_{\text {field }}+\varepsilon_{\text {sat }}
$$

$\hat{\Theta}_{\text {sat }}$ refers to satellite measurements and $\varepsilon_{\text {sat }}$ to the random satellite measurement error. Calculating the average of squared differences of collocated upscaled in-situ measurements and satellite observations leads to the MSD or, more common when taking the square root, to the Root-Mean-Square-Difference (RMSD). This is an often used validation metric and represents the following (given the previously described assumptions):

$$
\left\langle\left(\hat{\Theta}_{i n s}^{*}-\hat{\Theta}_{s a t}\right)^{2}\right\rangle=\varepsilon_{i n s}^{* 2}-2 \varepsilon_{i n s}^{*} \varepsilon_{s a t}+\varepsilon_{s a t}^{2}
$$

The Gaussian brackets indicate an averaging over all collocated measurements. From Equation (2.6) it becomes clear that even if the in-situ sensor would measure true point-scale soil moisture, the random part of the upscaling error, i.e. the representativeness error, might significantly inflate the MSD compared to the actual satellite error.

Let us now consider a third data set (e.g., a land surface model), also scaled to the satellite observations:

$$
\hat{\Theta}_{m o d}^{*}=\Theta_{f i e l d}+\varepsilon_{\text {mod }}^{*}
$$


$\hat{\Theta}_{\text {mod }}^{*}$ refers to rescaled modelled soil moisture estimates and $\varepsilon_{\text {mod }}^{*}$ to the rescaling error plus the rescaled random model error. Cross-multiplying now the differences between three collocated data sets instead of using squared differences of two data sets leads to the core equations of the triple collocation:

$$
\begin{aligned}
& \left\langle\left(\hat{\Theta}_{i n s}^{*}-\hat{\Theta}_{s a t}\right)\left(\hat{\Theta}_{i n s}^{*}-\hat{\Theta}_{m o d}^{*}\right)\right\rangle=\left\langle\varepsilon_{i n s}^{* 2}-\varepsilon_{i n s}^{*} \varepsilon_{s a t}-\varepsilon_{i n s}^{*} \varepsilon_{m o d}^{*}+\varepsilon_{s a t} \varepsilon_{m o d}^{*}\right\rangle \\
& \left\langle\left(\hat{\Theta}_{\text {sat }}-\hat{\Theta}_{i n s}^{*}\right)\left(\hat{\Theta}_{\text {sat }}-\hat{\Theta}_{\text {mod }}^{*}\right)\right\rangle=\left\langle\varepsilon_{\text {sat }}^{2}-\varepsilon_{\text {sat }} \varepsilon_{\text {ins }}^{*}-\varepsilon_{\text {sat }} \varepsilon_{\text {mod }}^{*}+\varepsilon_{\text {ins }}^{*} \varepsilon_{\text {mod }}^{*}\right\rangle \\
& \left\langle\left(\hat{\Theta}_{m o d}^{*}-\hat{\Theta}_{i n s}^{*}\right)\left(\hat{\Theta}_{m o d}^{*}-\hat{\Theta}_{s a t}\right)\right\rangle=\left\langle\varepsilon_{m o d}^{* 2}-\varepsilon_{m o d}^{*} \varepsilon_{i n s}^{*}-\varepsilon_{m o d}^{*} \varepsilon_{s a t}+\varepsilon_{i n s}^{*} \varepsilon_{s a t}\right\rangle
\end{aligned}
$$

Given the errors are Gaussian and that a sufficient number of measurements are averaged we get following relationships:

$$
\begin{aligned}
\left\langle\varepsilon_{i}{ }^{2}\right\rangle & =\operatorname{Var}\left(\varepsilon_{i}\right) \\
\left\langle\varepsilon_{i} \varepsilon_{j}\right\rangle & =\operatorname{Cov}\left(\varepsilon_{i} \varepsilon_{j}\right) \quad, \quad i \neq j
\end{aligned}
$$

$\operatorname{Var}\left(\varepsilon_{i}\right)$ and $\operatorname{Cov}\left(\varepsilon_{i} \varepsilon_{j}\right)$ are the error variances and -covariances, respectively. If the errors are uncorrelated, Equation (2.8) reduces to the following:

$$
\begin{aligned}
&\left\langle\left(\hat{\Theta}_{i n s}^{*}-\hat{\Theta}_{s a t}\right)\left(\hat{\Theta}_{i n s}^{*}-\hat{\Theta}_{m o d}^{*}\right)\right\rangle=\hat{e}_{i n s}^{*} \\
&\left\langle\left(\hat{\Theta}_{\text {sat }}-\hat{\Theta}_{i n s}^{*}\right)\left(\hat{\Theta}_{\text {sat }}-\hat{\Theta}_{m o d}^{*}\right)\right\rangle=\hat{e}_{\text {sat }} \\
&\left\langle\left(\hat{\Theta}_{\text {mod }}^{*}-\hat{\Theta}_{i n s}^{*}\right)\left(\hat{\Theta}_{m o d}^{*}-\hat{\Theta}_{s a t}\right)\right\rangle=\hat{e}_{m o d}^{*} \\
& \hat{e}_{i}=\left\langle\varepsilon_{i}^{2}\right\rangle
\end{aligned}
$$

$\hat{e}_{i}$ are the finally obtained error estimates, representing the average random errors of the individual data sets independent of each other.

\subsubsection{Underlying assumptions}

In the derivation of the triple collocation several very important assumptions were made:

1 All three data sets are somehow representative for a same water volume

2 The rescaling of two data sets to one randomly chosen reference, in this case the satellite data set, removes the systematic scale differences between them

3 The errors of the three data sets are not correlated with each other

4 A sufficient number of temporally collocated triplets are available so that error covariances vanish end the mean data set errors remain after the averaging. 
If Assumption 1 is not fulfilled, true soil moisture $\Theta_{\text {field }}$ would not vanish in Equation (2.8) and the errors were significantly inflated. Usually the relationship between the three data sets is evaluated using their temporal correlation. The most common approach is to calculate the correlation significance based on the Student's t test. In this study a probability threshold of 0.05 is used. However, this might not always be appropriate because for a very large number of triplets almost every correlation level is considered as being significant. Conversely, in very dry areas such as deserts, a very high noise level might overlay the actual soil moisture signal leading to very low correlations. Such areas would be filtered according to the t-test. Nevertheless it would be of high interest to use the triple collocation there to estimate the actual noise level. The feasibility of applying the triple collocation over such areas is still a research topic but not part of this study. Assumption $\mathbf{2}$ is only fulfilled if the statistic relationship across the scales is well described in the rescaling model. In some regions, the high complexity of spatio-temporal soil moisture variability across scales might require also the correction for higher-order statistical moments when using data sets with a large scale difference. If this is not done sufficiently the random error estimate are artificially inflated. The rescaling methods used in this study are discussed in Section 4.1. Furthermore, the rescaling also scales the random error estimates into the data space of the chosen reference. This is indicated with the asterisks in the error terms $e_{i n s}^{*}$ and $e_{\text {mod }}^{*}$ in Equation (2.10). Since the scaling coefficients are known the estimated errors could be transformed back, but for a meaningful inter-comparison they are usually kept in the same data space. Note that thus the quality of the chosen reference does not have an impact on the error estimates of the individual data sets but only on the dynamic range in which they are expressed. Hence, the choice of the reference also does not influence the relative contribution of scaling errors to the triple collocation error estimates, which will be discussed in Section 2.2.3. In the derivation of the method, the satellite data set was chosen as a reference to emphasize the upscaling process. Since soil moisture dynamics are highly varying globally and across scales, the in-situ measurements were used as a reference in this study in order to characterize the errors with respect to their local dynamics.

If Assumption 3 is not fulfilled, the co-variance terms in Equation (2.8) would not vanish and significantly inflate or deflate the actual error estimates. This could be the case when using for instance land surface models driven with the same input data sets or two frequency channels of one satellite. However, the data sets of this study use different physical measurement principles and are not driven by each other. Hence, zero error cross-correlation can be assumed.

Assumption 4 is also required for the error co-variance terms to vanish due to their Gaussian distribution and for the errors to represent the actual average of the entire data set. Figure 2.2 shows the relationship between the number of available measurement triplets, the average error level, and the error estimation stability, based on a simulation of Zwieback et al. (2012). The limited number of triplets introduces a noise in the estimate. 


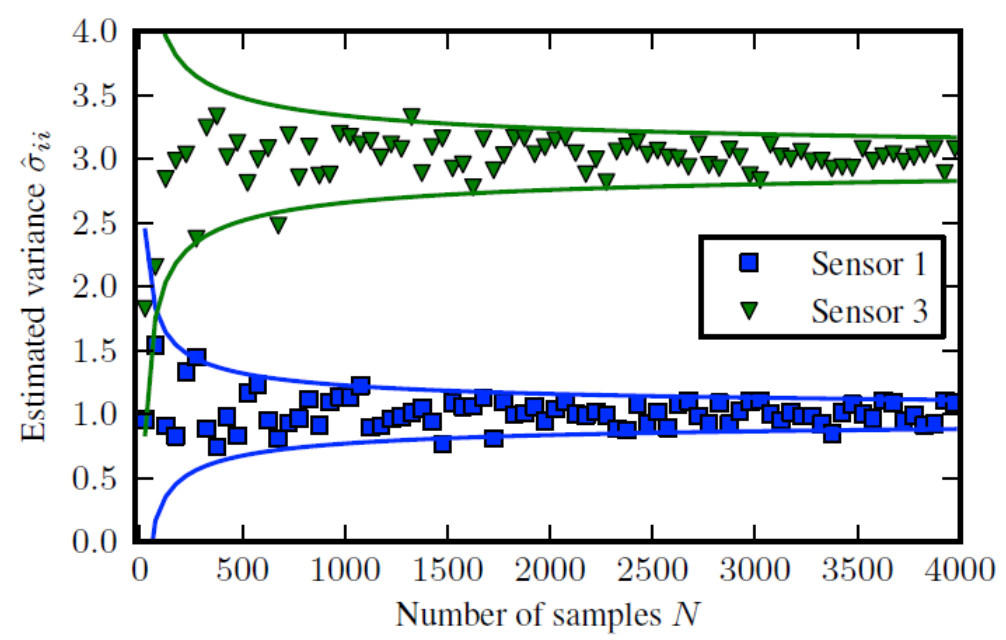

Figure 2.2: Relationship between the number of available measurement triplets, the average error level, and the error estimation stability of the triple collocation (Zwieback et al., 2012).

\subsubsection{Impact of random scaling errors}

As discussed above, the RMSD is a composite of the random errors of both data sets and the representativeness error. The triple collocation estimates the random errors of the data sets independent of the choice of a reference. The remaining question is to which data set the representativeness errors are attributed. In this study two coarse-scale and one in-situ data set are used. Soil moisture variations visible in two data sets are attributed to the third data set as representativeness errors (Stoffelen, 1998). Hence, soil moisture variations in the satellite and the model footprint not effecting the in-situ site will be considered as random errors in the in-situ data set. That is, the triple collocation can be used to estimate the representativeness errors of in-situ stations. Figure 2.3 shows a very good agreement between estimated errors using the triple collocation and the actual representativeness errors (in the figure referred as upscaling errors) based on a study of Miralles et al. (2010). The actual upscaling error was estimated using a high-density network. This behaviour of the triple collocation forms the basis of this study, in which the it will be used to estimate errors in the coarse-scale representation of more than 1400 globally distributed in-situ stations. The used data sets and the implementation of the triple collocation method will be discussed in the following chapters. 


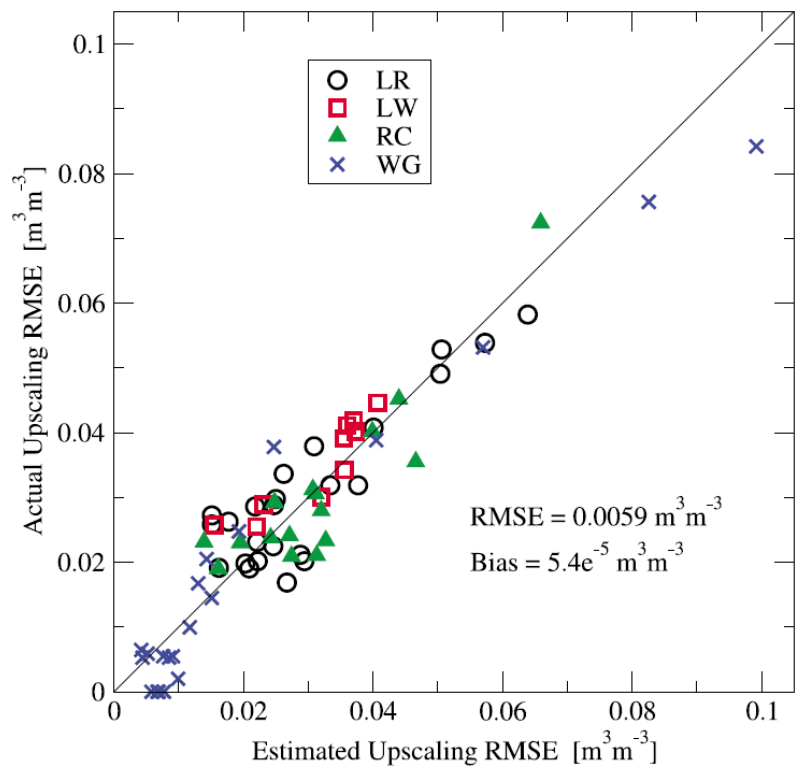

Figure 2.3: Relationship between estimated and actual representativeness errors (Crow et al., 2012). 


\section{Chapter 3}

\section{Data Sets}

Random errors of the ISMN are assessed using the triple collocation method, which requires two additional data sources with independent error structures. A blended active and passive remotely sensed data set and the ERA-Interim reanalysis data set were used for this purpose as they have the biggest temporal overlap with the available in-situ measurements. The global Koeppen-Geiger map was used to relate the stations to climate classes. Soil texture information was drawn from the Harmonized World Soil Database (HWSD).

\subsection{In-situ soil moisture measurements}

The ISMN (http://www.ipf.tuwien.ac.at/insitu) is a centralized data hosting facility. It collects soil moisture ground measurements and, if available, ancillary measurements such as precipitation, soil temperature, air temperature, snow depth, and snow water equivalent from operational and experimental networks worldwide (Dorigo et al., 2011a,b). As there are no standard methods yet for collecting soil moisture data in-situ, the data sets are usually highly different in terms of sensor installation depths and placement, temporal sampling, used units, and data formats. The ISMN harmonizes incoming data sets in terms of units, sampling interval, data format, and metadata and makes them available to users costfree from a single web portal. Initiated by the European Space Agency (ESA) in 2010 and operated by the Vienna University of Technology (TU Wien), it has evolved as one of the most important in-situ soil moisture data platforms for satellite and land surface model validation (e.g., Albergel et al., 2012; Liu et al., 2012). Providing networks operate one or more geographically distributed stations which typically place a variety of sensors to cover different depths but also to increase the measurement reliability by making redundant measurements with equal sensors in the same depths close to each other. Currently (October 2012), the ISMN holds the measurements of over 6100 soil moisture sensors, provided by 35 different networks, which operate together more than 1400 stations. Data providers are listed in the Acknowledgments. Figure 3.1 illustrates the global station distribution. Most of them are located in Northern America and Eurasia and spread over a variety of climate regions, land 
cover types, and soil textures. The temporal coverage of each network is shown in Figure 3.2. Data sets cover a time period from 1952 (historical data sets) to now, while six networks with together more than 200 stations are operating in near real time (NRT). A large variety of sensor types are used, placed at different depths, and representing different depth intervals. Table 3.1 gives an overview of the used sensors and depth placements for each network. Available sensors make use of different measurement principles such as time domain reflectometry (TDR), frequency domain reflectometry (FDR), capacitance probes, impedance probes, neutron probes, cosmic ray probes, and gravimetric measurements, all of which results in different sampling intervals and data accuracy (Mittelbach et al., 2011, 2012; Plauborg et al., 2005; Walker et al., 2004). For this study, the sensor types were summarized into five groups after similar properties: gravimetric, capacitance, TDR/FDR, impedance, cosmic ray, and neutron probes.

Only data sets that achieve the statistical requirements of the triple collocation were used (See Methodology). All available sensor depths were used to investigate the error dependency on the measurement depth. Soil texture and climate region analysis were based on surface measurements only, i.e., on measurements of which the start of the measurement interval lies between $\mathrm{o}$ and 10 $\mathrm{cm}$.

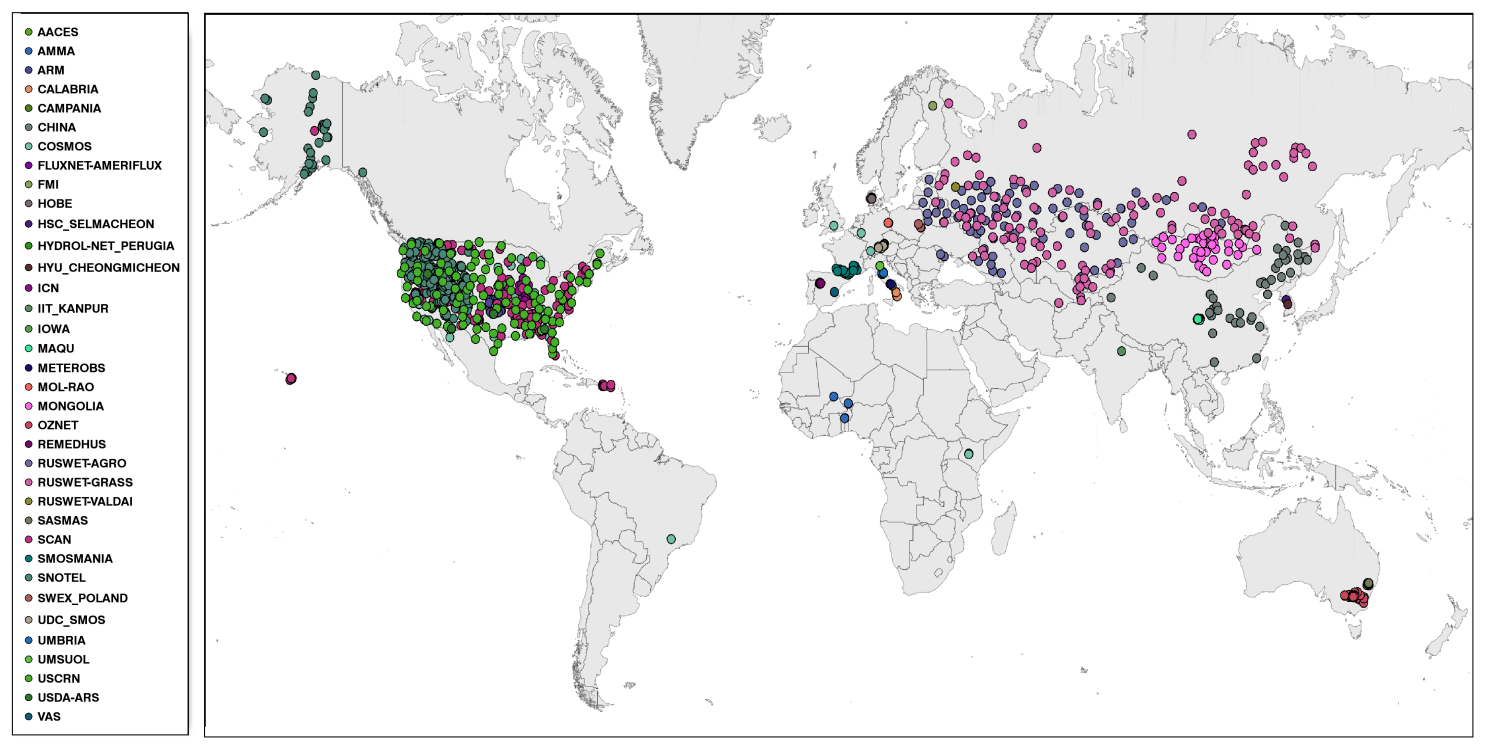

Figure 3.1: Station distribution of the International Soil Moisture Network (ISNM; October 2012). Pins represent single stations, colors represent different networks. 


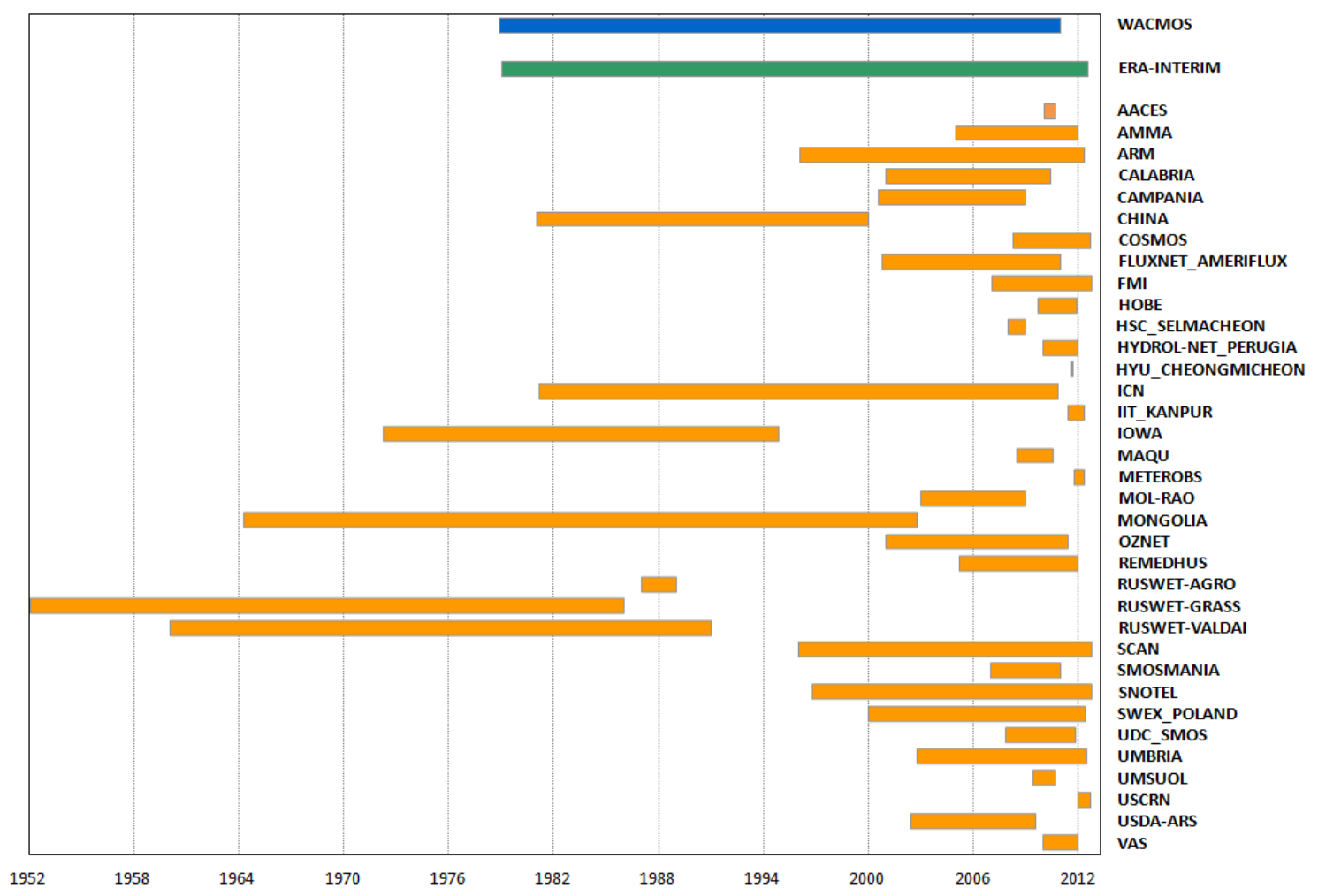

Figure 3.2: Temporal coverage of the International Soil Moisture Network (ISMN) networks, Water Cycle Multi-Mission Observation Strategy (WACMOS) and ERA-Interim. 
Table 3.1: Overview of the number of stations, the used sensors, the total observed depth range, and the number of sensor placements in different depths for each network, respectively. [ $\left.{ }^{*}\right]$ The Cosmic Ray Probe sensing depth depends on the apparent water content.

\begin{tabular}{|c|c|c|c|c|}
\hline Network & Stations & Sensors & Depth covered & \# depth placements \\
\hline AACES & 49 & ThetaProbe ML2X & $0.00-0.25$ & 3 \\
\hline AMMA & 7 & CS616 & $0.05-1.20$ & 13 \\
\hline ARM & 25 & $\begin{array}{l}\text { SMP1 } \\
\text { Water Matric Potential Sensor 229L }\end{array}$ & $0.03-1.75$ & 10 \\
\hline CALABRIA & 5 & ThetaProbe ML2X & $0.30-0.90$ & 3 \\
\hline CAMPANIA & 2 & ThetaProbe ML2X & $0.30-0.30$ & 1 \\
\hline CHINA & 40 & Coring device/auger & $0.00-1.00$ & 11 \\
\hline COSMOS & 67 & Cosmic-ray Probe & {$\left[{ }^{*}\right]$} & - \\
\hline FLUXNET-AMERIFLUX & 2 & $\begin{array}{l}\text { Moisture Point PRB-K } \\
\text { ThetaProbe ML2X }\end{array}$ & $0.00-0.50$ & 8 \\
\hline FMI & 1 & ThetaProbe ML2X & $0.02-0.10$ & 2 \\
\hline HOBE & 30 & Decagon $5 \mathrm{TE}$ & $0.00-0.55$ & 3 \\
\hline HSC_SEMACHEON & 1 & Hydraprobe Analog (CR8oo) & $0.00-0.10$ & 1 \\
\hline HYDROL-NET_PERUGIOA & 1 & TDR TRASE-BE & $0.05-0.35$ & 4 \\
\hline HYU_CHEONGMICHEON & 1 & Hydraprobe T10ooA & $0.00-0.10$ & 1 \\
\hline ICN & 19 & $\begin{array}{l}\text { Stevens Hydra Probe } \\
\text { Troxler Neutron Surface Probe } \\
\text { Troxler Neutron Depth Probe }\end{array}$ & $0.00-2.00$ & 11 \\
\hline IIT_KANPUR & 1 & Water Scout SMioo & $0.10-0.80$ & 4 \\
\hline IOWA & 6 & N.S. & $0.00-2.59$ & 12 \\
\hline MAQU & 20 & $\mathrm{ECH} 20 \mathrm{EC}-\mathrm{TM}$ & $0.05-0.05$ & 1 \\
\hline METEROBS & 1 & EnviroSCAN & $0.10-0.50$ & 5 \\
\hline MOL-RAO & 2 & TRIME-EZ & $0.08-1.50$ & 9 \\
\hline MONGOLIA & 44 & Coring device/auger & $0.00-1.00$ & 10 \\
\hline OZNET & 38 & $\begin{array}{l}\text { CS615 } \\
\text { CS616 } \\
\text { EnviroSCAN } \\
\text { Stevens Hydra Probe }\end{array}$ & $0.00-0.90$ & 7 \\
\hline REMEDHUS & 23 & Stevens Hydra Probe & $0.00-0.05$ & 1 \\
\hline RUSWET-AGRO & 156 & Gravimetric & $0.00-1.00$ & 2 \\
\hline RUSWET-GRASS & 122 & Gravimetric & $0.00-1.00$ & 2 \\
\hline RUSWET-VALDAI & 3 & Gravimetric & $0.00-1.00$ & 3 \\
\hline SASMAS & 14 & $\begin{array}{l}\text { CS616 } \\
\text { Stevens Hydra Probe }\end{array}$ & $0.00-0.30$ & 2 \\
\hline SCAN & 182 & $\begin{array}{l}\text { Hydraprobe Analog (2.5 Volt) } \\
\text { Hydraprobe Analog (5.0 Volt) } \\
\text { Hydraprobe Digital Sdi-12 (2.5 Volt) } \\
\text { N.S. }\end{array}$ & $0.03-2.03$ & 24 \\
\hline SMOSMANIA & 21 & ThetaProbe ML2X & $0.05-0.30$ & 4 \\
\hline SNOTEL & 374 & $\begin{array}{l}\text { Hydraprobe Analog (2.5 Volt) } \\
\text { Hydraprobe Analog (5.0 Volt) } \\
\text { Hydraprobe Digital Sdi-12 (2.5 Volt) } \\
\text { N.S. }\end{array}$ & $0.00-1.02$ & 16 \\
\hline SWEX_POLAND & 6 & $\begin{array}{l}\text { D-LOG-mpts } \\
\text { PR2- Profile Probe }\end{array}$ & $0.00-1.00$ & 10 \\
\hline UDC_SMOS & 11 & $\begin{array}{l}\text { EC-ET } \\
\text { EC5 } \\
\text { IMKO TDR }\end{array}$ & $0.00-0.40$ & 5 \\
\hline UMBRIA & 7 & $\begin{array}{l}\text { EnviroSCAN } \\
\text { ThetaProbe } \mathrm{ML}_{2} \mathrm{X}\end{array}$ & $0.05-0.45$ & 3 \\
\hline UMSUOL & 1 & TDR 100 & $0.10-1.80$ & 7 \\
\hline USCRN & 114 & Stevens Hydraprobe II Sdi-12 & $0.05-1.00$ & 5 \\
\hline USDA-ARS & 4 & Hydraprobe Analog (2.5 Volt) & $0.00-0.05$ & 1 \\
\hline VAS & 2 & $\begin{array}{l}\text { Stevens Hydra Probe } \\
\text { ThetaProbe ML2X }\end{array}$ & $0.00-0.05$ & 1 \\
\hline
\end{tabular}




\subsection{Remotely Sensed Soil Moisture}

The satellite data set used in this study was the data set created within the Water Cycle MultiMission Observation Strategy project (WACMOS; http://www .esa-soilmoisture-cci.org), released in June 2012 within the framework of the Climate Change Initiative (CCI). It is the first available long-term remotely sensed soil moisture product covering a 32 year period from 1978 to 2010, providing data in $0.25^{\circ}$ spatial resolution and was generated by merging active and passive soil moisture estimates from various satellite missions (Liu et al., 2011, 2012). Merging different instruments from various satellites based on their temporal availability causes an increase of data quality with time. The temporal resolution is approximately $1-3$ days.

\subsection{Modelled soil moisture}

ERA-Interim is a global atmospheric reanalysis data set combined with an ocean and land surface model produced by the European Centre for Medium-range Weather Forecasts (ECMWF; Dee et al., 2011). It covers a time period from 1979 to June 2012 and provides data in a spatial resolution of $\left(\sim 0.7^{\circ}\right)$ at the equator. Soil moisture estimates are provided for four different layers $(0-7,7-28$, 28-100, and 100-255 cm) four times each day (0:00, 6:00, 12:00, and 18:00) for two different land surface schemes (TESSEL and HTESSEL; Balsamo et al., 2009). The HTESSEL scheme was used in this study because it provides a more realistic representation of the soil than the TESSEL scheme by distinguishing between six different soil types around the globe instead of just one. ERA-Interim also provides soil temperature estimates for the respective layers and an estimate of snow height. These were used to mask soil moisture measurements for which the temperature is below $0^{\circ} \mathrm{C}$ and for which the snow cover estimate is greater than zero, as both satellites and most of the in-situ sensors are making use of electromagnetic properties of the soil, which significantly change when the soil is frozen (Ulaby et al., 1982).

\subsection{Koeppen-Geiger Climate Classification}

The Koeppen-Geiger classification divides the globe into climate regions based on their temperature and precipitation regime. The updated world map from Peel et al. (2007) was used for this study (http://www.hydrol-earth-syst-sci.net/11/1633/2007/ hess-11-1633-2007-supplement .zip, accessed 25 July 2011). It contains a static map on a 0.1 degree grid based on long-term in-situ observations between 1951 and 2000. 


\subsection{Harmonized World Soil Database}

The Harmonized World Soil Database (HWSD; http: //webarchive . iiasa . ac . at/Research/ LUC/External-World-soil-database/HTML/) is a merged and harmonized product from various soil information sources providing information about soil properties such as material fractions, bulk density, or texture classes on a 1-km grid (Nachtergaele and Batjes, 2012). For this study, only the USDA soil texture classification is used, which for two layers (topsoil: $0-30 \mathrm{~cm}$, subsoil: $30-100 \mathrm{~cm}$ ) classifies the soil in the dominant fraction of clay, silt, and sand. 


\section{Chapter 4}

\section{Methodology}

\subsection{Implementation of the Triple Collocation}

Varying input settings have a high impact on the reliability of the result as well as on its actual meaning (Dorigo et al., 2010; Zwieback et al., 2012). Applied to the original soil moisture values, the result provides information about the ability of measuring absolute soil moisture whereas the use of soil moisture anomalies gives information about the capability of catching drying and wetting events, e.g., through precipitation (Dorigo et al., 2010). In this study, the triple collocation was applied on both original values and anomalies. As discussed in Section 2.2, the choice of the rescaling method may significantly change the result if the data sets are different in their statistical properties. The choice of an inappropriate rescaling technique will artificially inflate the error estimates in addition to the inherent errors caused by a mismatch in the spatial representativeness. Furthermore, the choice of the reference data set in the triple collocation determines the data space in which the errors are expressed. According to Section 2.2.2, the in-situ measurements were always used as a reference in order to characterize the errors with respect to their local dynamics. As discussed in Section 2.2.2, a sufficient number of triplets is required to obtain stable error estimates. For this study we decided that at least 100 triplets must be available.

\subsubsection{Rescaling of original estimates}

Kumar et al. (2012) found that slight non-linearities exist between soil moisture data sources, leading to improved scaling results for cumulative distribution function (CDF)-matching techniques compared to linear approaches. The CDF-method matches the cumulated distribution function of the data sets and hence corrects for non-linearities by correcting theoretically all higher statistical moments (Reichle and Koster, 2004). Depending on the implementation, mainly mean, standard deviation, skewness, and kurtosis are affected. We choose to apply it when using absolute soil moisture measurements as a stepwise linear scaling between a set of percentiles of the data ( $\mathrm{Liu}$ et al., 2011). 


\subsubsection{Anomalies}

Anomalies usually are the difference between actual measurements and the long-term climatology. However, if data sets do not have a sufficient temporal coverage, climatologies cannot be computed reliably. Another way of calculating anomalies is to use a moving average window to create a baseline for the subtraction (e.g., Albergel et al., 2012), as shown in Equation (4.1):

$$
\Theta_{A}(t)=\Theta(t)-\overline{\Theta(W)}
$$

$\Theta_{A}$ is the soil moisture anomaly, $\Theta$ the observed absolute soil moisture, $t$ the time of acquisition, and $W$ the length of the moving window. An appropriate window length allows for removing systematic differences between different data sources which would be interpreted as random errors, while preserving the response of the individual data sets to short-term drying and wetting events (e.g., the seasonal vegetation growing cycles strongly effect satellite observations, but not in-situ measurements). We chose a window length of 5 weeks $(t \pm 17 d)$ according to Albergel et al. (2012). The anomaly is only computed when at least five measurements are available within the respective window, even though most in-situ stations provide an hourly measurement rate.

The anomalies of remotely sensed and ERA-Interim soil moisture were scaled to those of the insitu sensors using a normalization approach that matches the mean and the standard deviation as shown in Equation (4.2) (Dorigo et al., 2010):

$$
\Theta_{A, S}^{*}(t)=\overline{\Theta_{A, R}}+\sqrt{\frac{\operatorname{Var}\left(\Theta_{A, R}\right)}{\operatorname{Var}\left(\Theta_{A, S}\right)}}\left[\Theta_{A, S}(t)-\overline{\Theta_{A, S}}\right]
$$

$\Theta_{A, S}(t)$ is the anomaly at the time $t, \Theta_{A, R}$ the reference anomaly data set, $\operatorname{Var}()$ refers to the variance, and the overline to the mean value. $\Theta_{A, S}^{*}(t)$ is the rescaled measurement at the time $t$.

\subsubsection{Spatial and temporal collocation}

The spatial collocation was performed by using the in-situ stations as a reference and searching the respective satellite and ERA-Interim ground point closest to the station.

In-situ sensors cover a varying depth-range, whereas the ERA-Interim data set represents four fixed layers (see ERA-Interim). Since the in-situ measurements sometimes overlap with more than one ERA-Interim layer, a depth-collocation was performed by assigning the sensor depth to the ERAInterim layer that covers the start of its measurement interval (e.g., the $0-7 \mathrm{~cm}$ layer of ERA-Interim is used when the sensor is placed in 5-10 cm). The same depth collocation was done for the two layers of the Harmonized World Soil Database. 

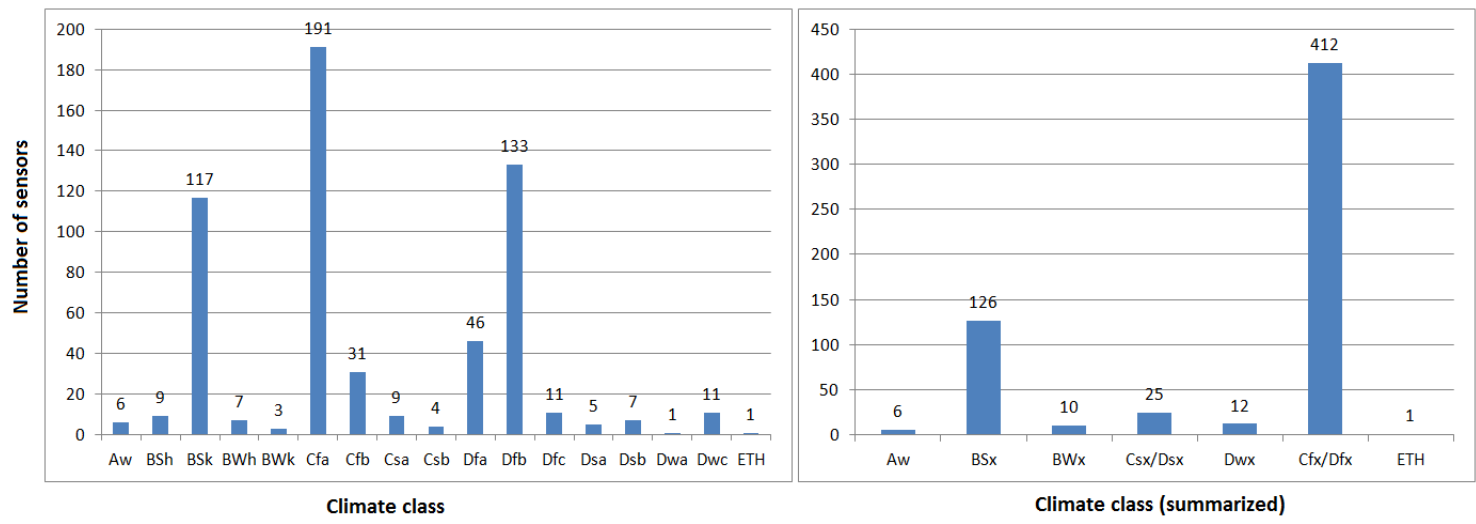

Figure 4.1: Distribution of available measurements within the original Koeppen-Geiger classes (left) and the summarized classes (right).

For the temporal collocation, the data source with the lowest measuring frequency, which was the remote sensing data set, was taken as a reference to search for the closest valid measurement of the other sources with a maximum difference of $\pm 3 h$.

\subsection{Analysis}

\subsubsection{Sensor quality on a network, depth and sensor type level}

The aim is to evaluate (i) whether the error estimates (including both, measurement errors and representativeness errors) change with sensor positioning or for different sensor types, (ii) whether some measurements show different error levels when looking into anomalies instead of absolute values, and (iii) whether there are networks that provide more reliable measurements than others. The error estimates were therefore grouped with respect to the networks, the observation depths (the four ERA-Interim depth intervals were used to summarize the in-situ measurement depths as described in Section 4.1.3 and the used measurement techniques. Standard statistics (median, interquartile-range, and outliers) were computed for the comparison and the estimated errors of the absolute soil moisture measurements were plotted against the estimated errors of the anomalies.

\subsubsection{Climate class analysis}

The error estimates of the entire ISMN were grouped after the Koeppen-Geiger climate classes to evaluate a possible impact of the climate conditions on the measurement quality. We assumed that even though daily temperature fluctuations are known to cause variations in the sensor readings (Dorigo et al., 2013), an influence would be mainly driven by precipitation rather than by temperature regimes. Hence, we summarized climate classes with similar or equal precipitation 
Table 4.1: Koeppen-Geiger climate classes summarized by similar or equal precipitation regimes.

\begin{tabular}{ll}
\hline Summarized classes & Original classes \\
\hline Aw & Aw (Tropical-Savannah) BWx BWh (Arid-Desert-Hot) \\
BWk & (Arid-Desert-Cold) \\
BSx & BSh (Arid-Steppe-Hot) \\
& BSk (Arid-Steppe-Cold) \\
Csx/Dsx & Csa (Temperate-Dry Summer-Hot Summer) \\
& Csb (Temperate-Dry Summer-Warm Summer) \\
& Dsa (Cold-Dry Summer-Hot Summer) \\
& Dsb (Cold-Dry Summer-Warm Summer) \\
Dwx & Dwa (Cold-Dry Winter-Hot Summer) \\
& Dwc (Cold-Dry Winter-Cold Summer) \\
Cfx/Dfx & Cfa (Temperate-Without dry season-Hot Summer) \\
& Cfb (Temperate-Without dry season-Warm Summer) \\
& Dfa (Cold-Without dry season-Hot Summer) \\
& Dfb (Cold-Without dry season-Warm Summer) \\
& Dfc (Cold-Without dry season-Cold Summer) \\
ETH & ETH (Polar-Tundra-High Elevation) \\
\hline
\end{tabular}

patterns to increase the statistical significance. The grouping is shown in Table 4.1. The distribution of available measurements within the climate classes is shown in Figure 4.1. The estimated errors within the classes were furthermore compared to the median soil moisture state of the entire measurement period. We decided to consider only surface measurements for this analysis, i.e., measurements of which the start of the depth interval lies between o and $10 \mathrm{~cm}$, since we assumed that the biggest impact, if apparent, will be at the surface. Besides, the majority of sensors in the ISMN are placed close to the surface, so the surface measurements allow for the most meaningful inter-comparison because possible impacts of the depth mismatch between in-situ sensors and the satellite signal are reduced.

\subsubsection{Soil texture analysis}

In-situ sensors are placed over a large variety of soil types, which on the one hand influence soil moisture storage and redistribution properties (e.g., infiltration and evaporation rates or total water storage volume), and on the other hand show different responses to the physical measurement principle of the sensors. To evaluate a possible influence of the soil type on the measurement quality, we grouped the error estimates with respect to the USDA soil texture classes according to three dominant soil constituent types: Clay, silt, and sand (Table 4.2). The distribution of available measurements within the texture classes is shown in Figure 4.2. The estimated errors were again compared to the median soil moisture of the entire period. Only surface measurements were 


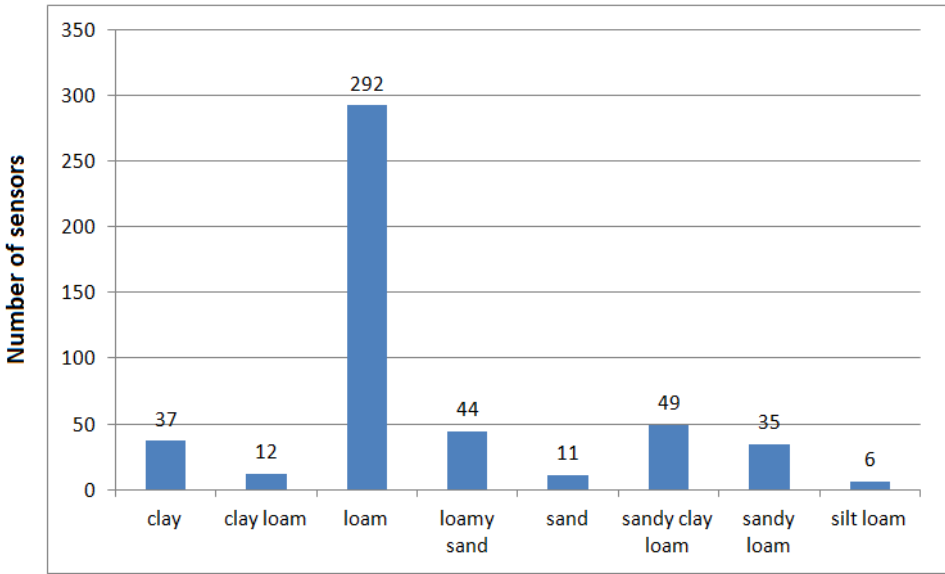

Soil texture class

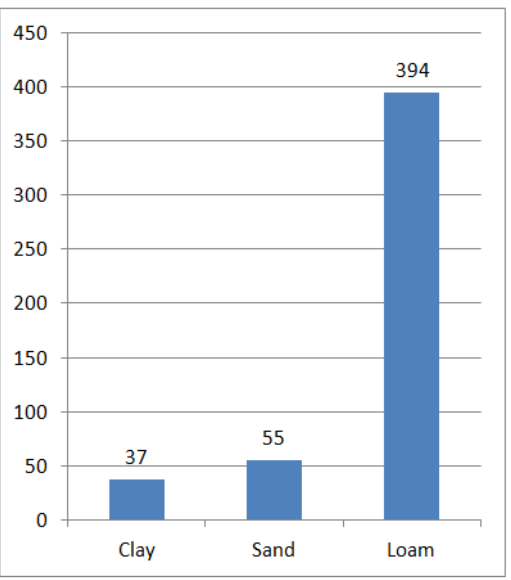

Soil texture class (summarized)

Figure 4.2: Distribution of available measurements within the original USDA soil texture classes (left) and the summarized classes (right).

considered for this analysis for the same reasons as for the climate class analysis. 
Table 4.2: USDA soil texture classes summarized by dominant soil types.

\begin{tabular}{ll}
\hline Summarized classes & Original classes \\
\hline Clay & clay (heavy) \\
& silty clay \\
& clay \\
& sandy clay \\
& sand \\
Sand & loamy sand \\
& sandy loam \\
Loam & sandy clay loam \\
& clay loam \\
& silty clay loam \\
& loam \\
& silt loam \\
\hline
\end{tabular}




\section{Chapter 5}

\section{Results and Discussion}

\subsection{Errors on a network, depth, and sensor type level}

Figure 5.1 shows statistics of error estimates of absolute soil moisture measurements for each network and measurement depth. The average error of the networks varies from about 0.02 to $0.06 \mathrm{~m}^{3} \mathrm{~m}^{-3}$. In addition, the error variability (in terms of the interquartile range; IQR) changes significantly between the networks from about 0.01 to $0.05 \mathrm{~m}^{3} \mathrm{~m}^{-3}$ with a pattern of increasing variability with increasing average error. A clear decrease in the measurement errors with increasing measurement depth can be seen for all networks except for the deepest layers of SCAN and SNOTEL. AMMA, ARM, and HOBE show a rather stable behavior. One reason for the observed error decrease with increasing measurement depth could be that the magnitude of daily temperature fluctuations, which are known to have an impact on the sensor readings (Dorigo et al., 2013) also decreases in deeper layers. Another possible explanation is the smoothing effect on the signal due to the decrease of temporal variability of soil moisture in deeper layers. Localized weather phenomena that effect the spatio-temporal variability and hence the spatial representativeness might also have a lower impact on deeper layers. Figure 5.2 shows the same statistics for different sensor types and measurement depths, again for absolute soil moisture measurements. All sensor types show a decrease of the errors with increasing depth, except for TDR/FDR and impedance probes placed in the deepest layer. That is, sensors placed in deeper layers might better represent coarse-scale soil moisture variations than shallow sensors. Note that the varying amount of measurements available to calculate the statistics for a certain network, depth or sensor type makes the statistics less robost (e.g., for AMMA, COSMOS, HYDROL-NET_PERUGIA, ICN, MOL-RAO, UMBRIA, UMSUOL, or cosmic ray and deep layer capacitance sensors) and might give a wrong impression of error variability under certain conditions. Several networks listed in Table 3.1 are not shown in the results because they either didn't fulfil the statistical requirements of the triple collocation method (i.e., were not significantly correlated with the satellite or the model) or had a too limited or no temporal overlap with the satellite and model data (i.e., less than 100 collocated measurement triplets). No error estimates for neutron probes and gravimetric measurements are shown for the same 


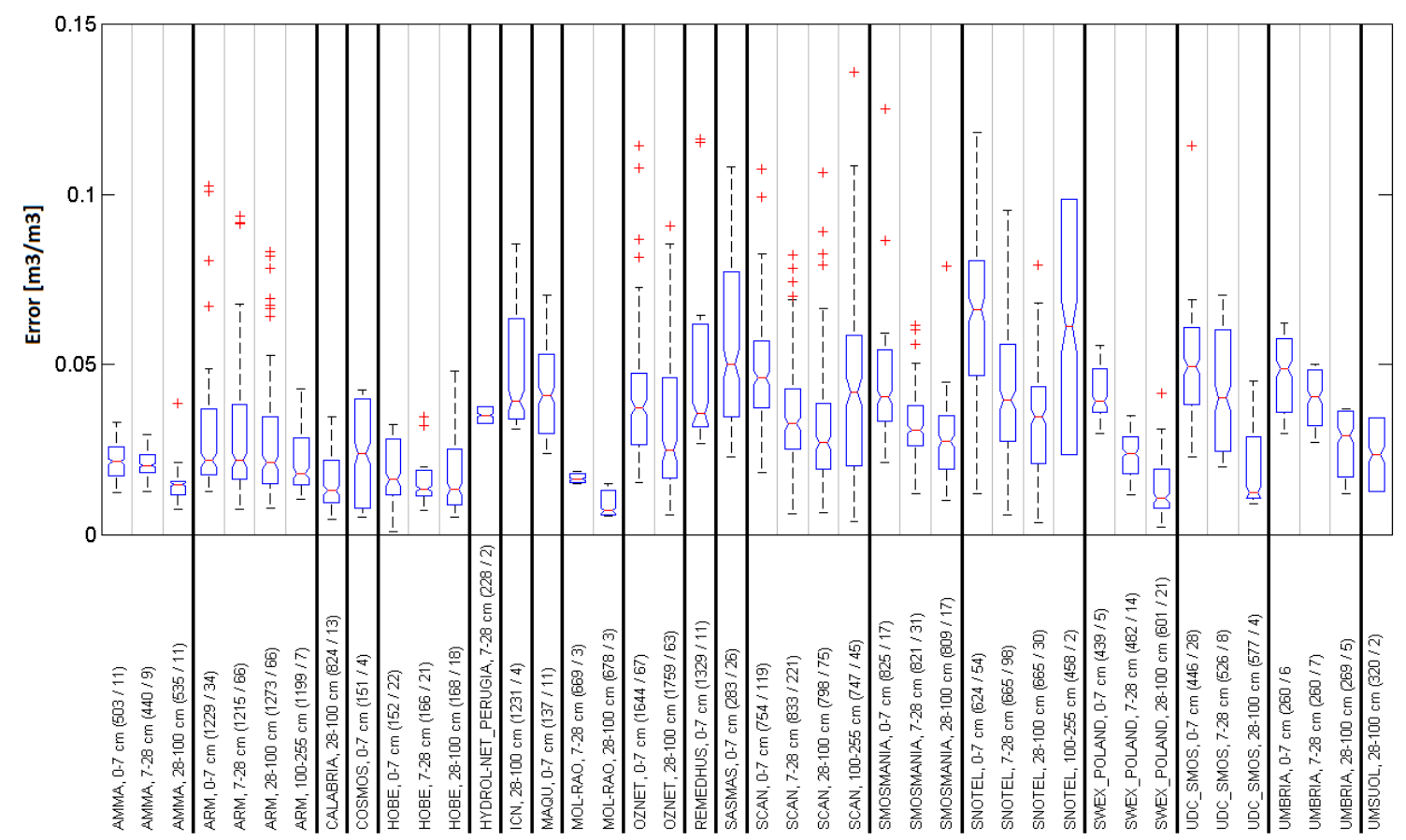

Figure 5.1: Box-Whiskers plot for the triple collocation result summarizing different observation depths of each network. The box represents the upper and lower quartile together with the median; the whisker length is 1.5 times the interquartile range drawn from the respective quartile. Red crosses indicate outliers exceeding the whiskers. Values in brackets show the average number of triplets used for the error estimate/the total number of error estimates used to calculate the statistic in the respective column.

reason. Above described patterns are similar when using anomalies instead of absolute soil moisture measurements. Figure 5.3 shows the error estimates for original values against error estimates for anomalies for all available measurements. One can see that, in general, errors of anomalies are lower than for absolute values with an increasing discrepancy for increasing errors. A trend for decreasing errors with increasing depth is again visible except for very deep measurements, which might be caused by the significantly lower number of error estimates in those depths. Soil moisture anomalies typically show a lower dynamic range than absolute soil moisture values, especially when calculating them as the difference from the moving-average baseline like it was done in this study. Hence, the data space in which the triple collocation expresses the errors show a lower dynamic range, which could support the impression of lower error estimates for anomalies. It is thus hard to distinguish whether soil moisture anomalies between the point scale and the coarse scale are closer related than absolute soil moisture values, or whether the different error levels are caused by the properties of the triple collocation. Also the dynamic range of absolute soil moisture measurements varies between the different networks and stations because of the different climate, soil, and terrain properties. Figure 5.4 shows the relationship between error estimates and the dynamic range of the measurements (expressed as the difference between the highest and the lowest measurement) 


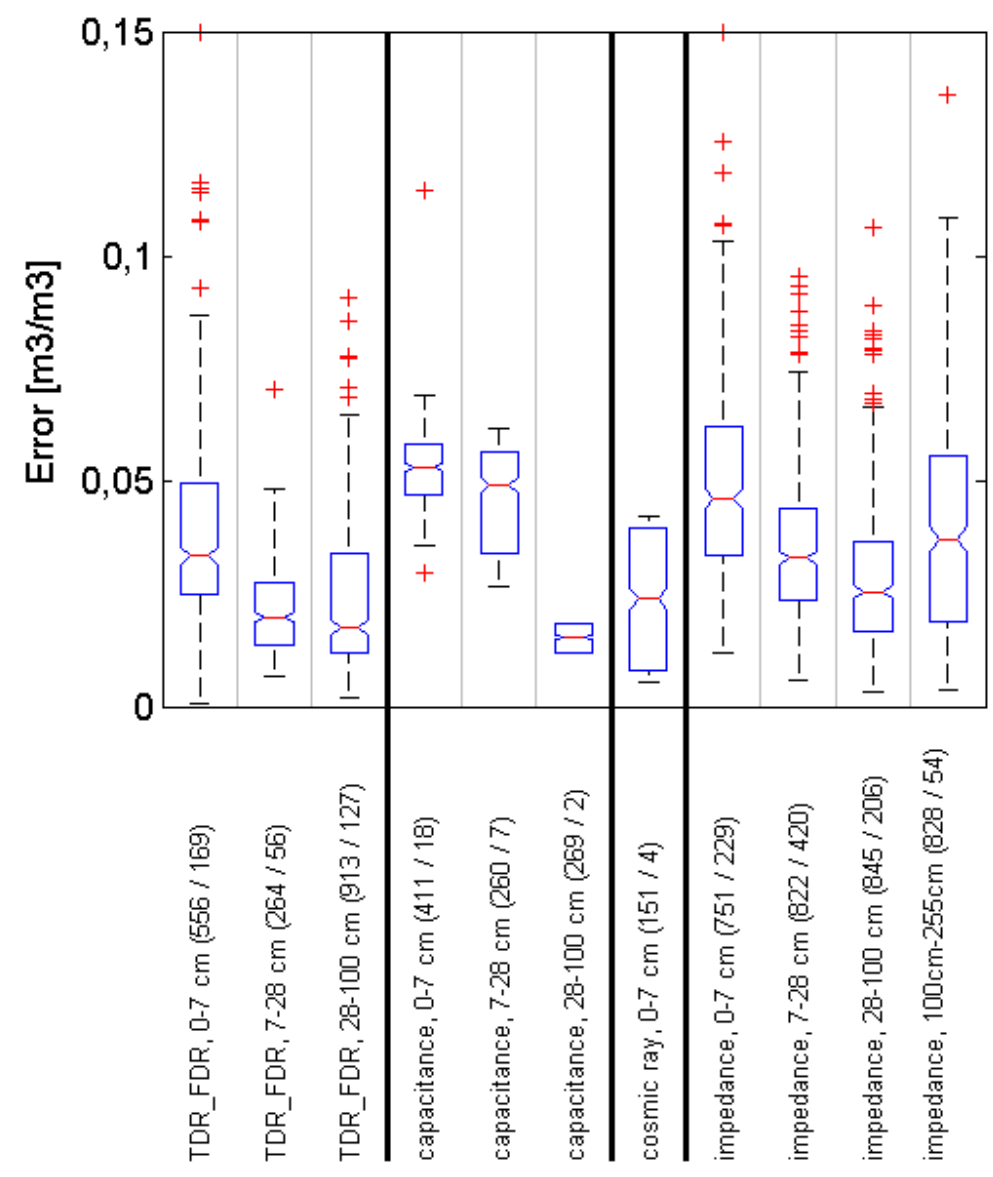

Figure 5.2: Box-whiskers plot for the triple collocation result summarizing different sensor types and depths. The box represents the upper and lower quartile together with the median; the whisker length is 1.5 times the interquartile range drawn from the respective quartile. Red crosses indicate outliers exceeding the whiskers. Values in brackets show the average number of triplets used for the error estimate/the total number of error estimates used to calculate the statistic in the respective column. 


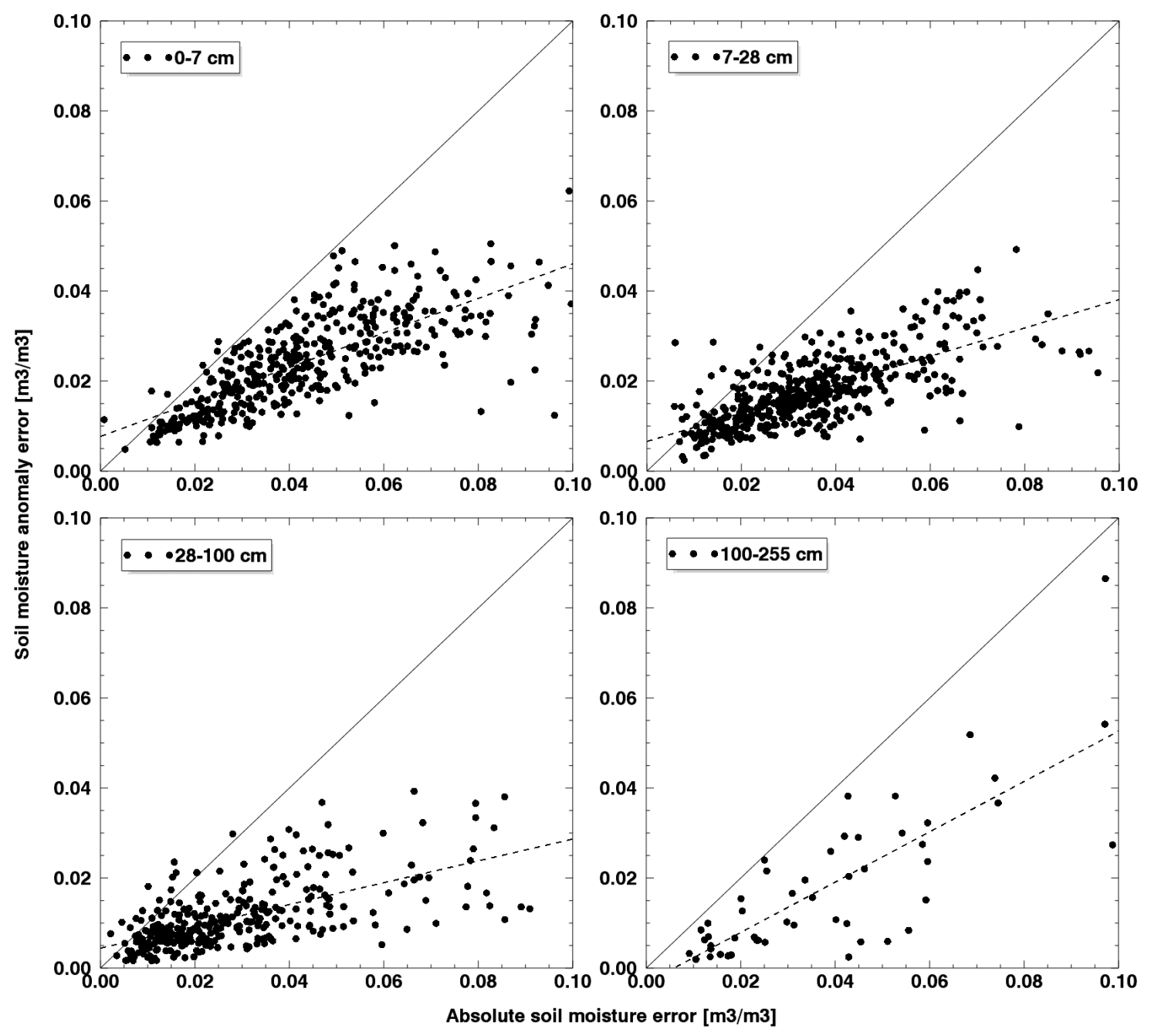

Figure 5.3: Estimated errors in the original measurements against estimated errors in anomalies summarized for different measurement depths. The dashed lines are the regression lines.

of all sensors of all used stations. One can see a clear trend of increasing error with increasing measurement variability. Again the two possible reasons for this are (i) that soil moisture at different scales is closer related when there is a lower overall soil moisture variability, i.e., point measurements are more representative under these conditions, and (ii) that the triple collocation artificially deflates errors with a low dynamic range.

\subsection{Climate class analysis}

Figure 5.5 shows the errors of measurements within different climate classes related to the median soil moisture at the respective site. One can see a clear trend of increasing errors for wetter average conditions in cold arid steppe regions. A similar trend can be seen for temperate and cold regions 


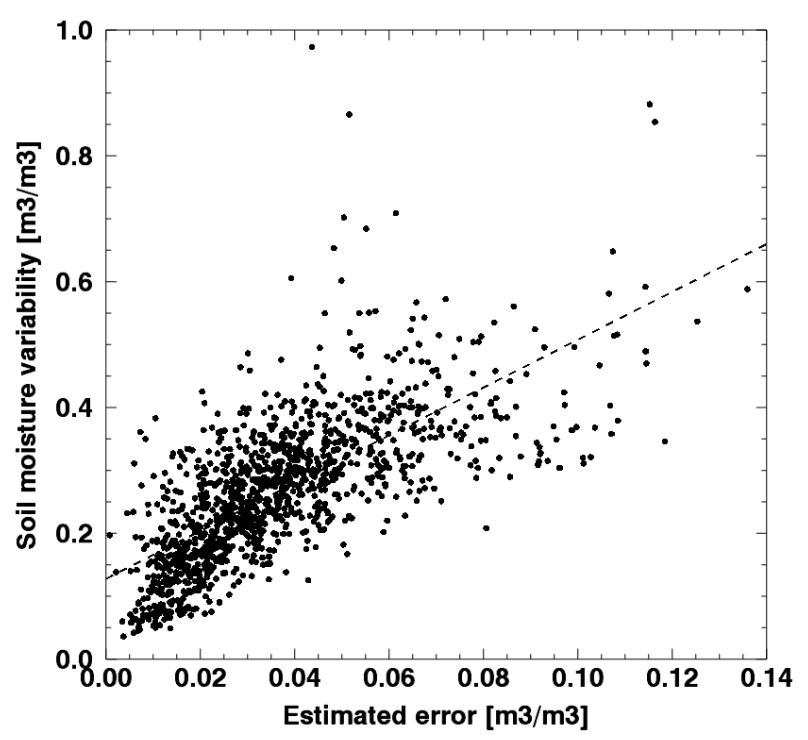

Figure 5.4: Error levels of absolute values against the soil moisture variability expressed as the difference between the highest and the lowest measurement. The dashed line is the regression line.

with dry summer as well as for arid desert regions, but very few data points are available to make this statement statistically reliable. This behavior is consistent with studies investigating inherent sensor errors (e.g., Mittelbach et al., 2011). Temperate and cold regions without a dry season appear to show two interfering phenomena pronounced as an apparent cross in the scatterplot: One trend for increasing errors with increasing average soil moisture and also a second trend for decreasing errors with increasing average soil moisture. Connecting the climate region to the soil type could not explain this behavior (not shown). A possible reason for the convex upward relationship between average soil moisture conditions and error levels is the spatio-temporal variability of soil moisture that reaches a maximum under intermediate wetness conditions (e.g., Brocca et al., 2012). Accordingly, sensors placed in such areas should be less representative for coarse-scale soil moisture than sensors placed in dry or wet areas. The interfering error peaks for very low and very high average soil moisture levels could not be explained and should be investigated in further studies. Too few or too randomly spread data points are available to see any pattern for tropical savannah, polar tundra and cold regions with dry winter. No significant differences in error budgets and hence the coarse-scale representativeness of the sensors are visible between particular climate regions. The impression of slightly lower errors in tropical savannah and arid desert regions might be caused by the lack of measurements in these regions. 

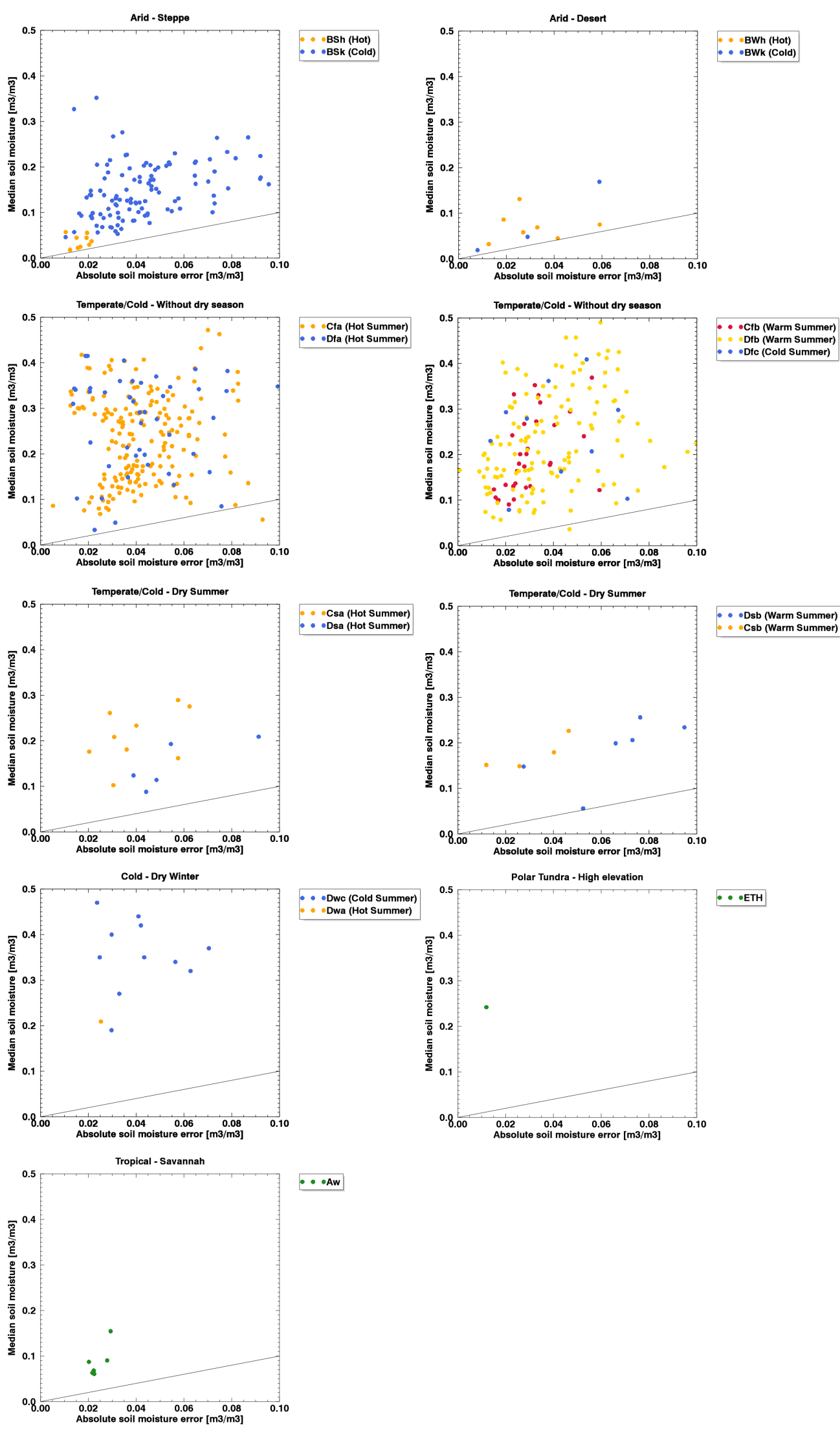

Figure 5.5: Errors in absolute values against the average soil moisture condition for summarized climate classes. Colors indicate the detailed classes according to the Koeppen-Geiger classification. 


\subsection{Soil texture analysis}

Figure 5.6 shows the errors of measurements within different soil types related to the median soil moisture at the respective site. Again, a slight trend of increasing errors with increasing average soil moisture conditions is visible but not as pronounced as for different climate regions. The same interfering trend of increasing errors with decreasing average soil moisture might be apparent in clay and loam but also less pronounced than for the climate classes. Sensors placed in sand appear to have slightly lower errors, but again statistically not significant. This could mean that soil moisture in sandy soils distributes more homogeneously over larger areas what makes single sensors placed in such soils more representative. The general reliability of the soil texture analysis is hampered by three facts: (i) the HWSD only represents dominant soil types in two coarse layers, (ii) the soil texture at the sites might significantly differ from the coarse-scale average soil texture provided from the HWSD, and (iii) several soil texture borders are following country borders instead of natural landscape features, questioning the reliability of the data sources. Site-specific soil texture information from the data providers would help to overcome this issue, but it is only available for very few networks. 

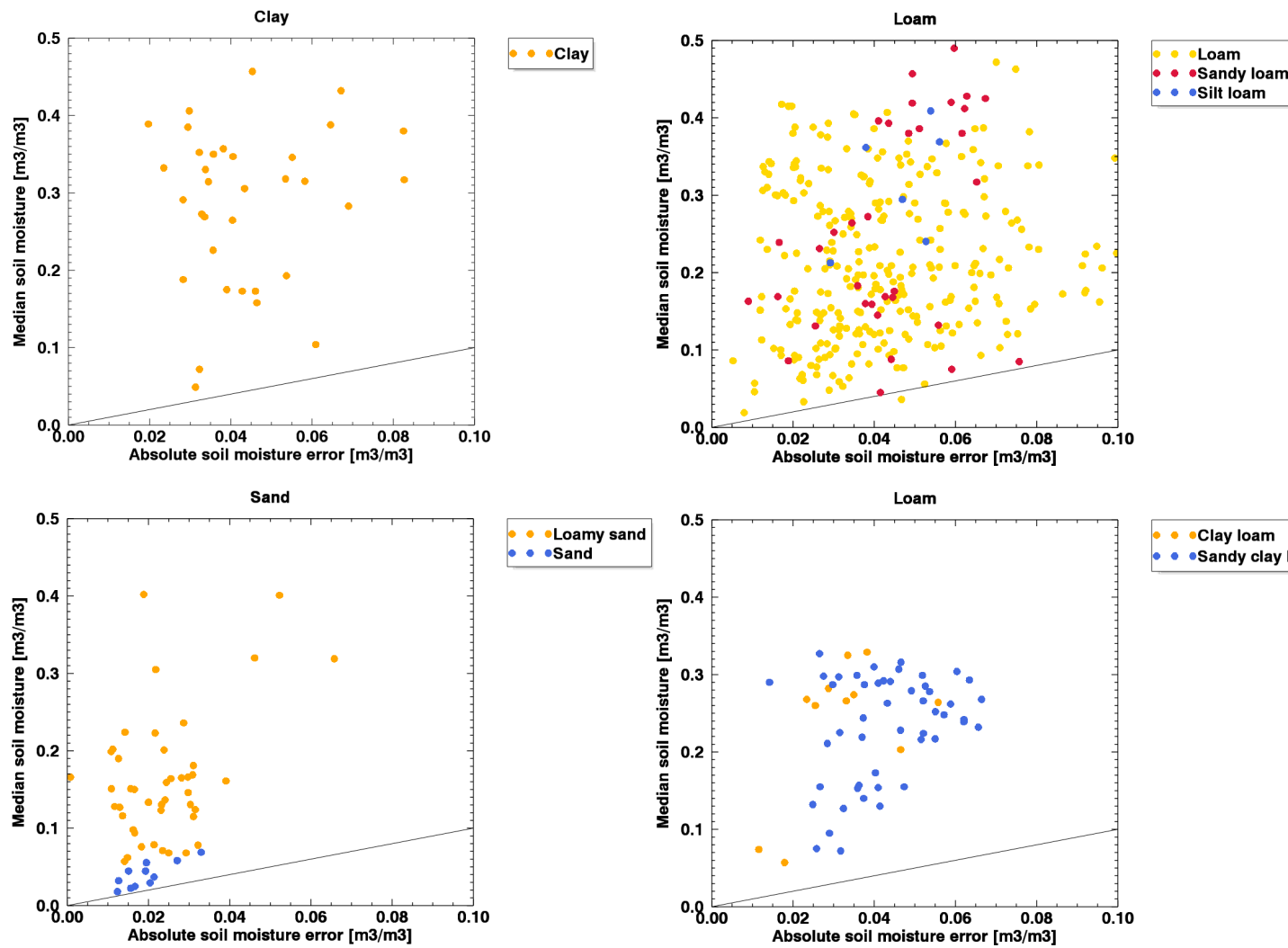

Figure 5.6: Errors in absolute values against the average soil moisture condition for summarized soil types. Colors indicate the detailed classes according to the USDA soil texture classification. The summarized class "loam" is splitted into two plots (right) for the visual separation of the contributing original classes. 


\section{Chapter 6}

\section{Conclusion and Outlook}

This study investigated the quality of in-situ measurements of the ISMN for representing soil moisture at footprint scales on a global basis using random error estimates of the triple collocation method. These errors reflect the actual inherent sensor measurement error, i.e., sensor noise and malfunctions, overlaid with external errors, which are (i) systematic differences between the statistical properties of the different data sources that cannot be removed with the CDFmatching and are hence interpreted as random errors, and (ii) scaling errors caused by the spatiotemporal variability of soil moisture, i.e., the limited spatial representativeness of the in-situ sensors (horizontally but also in depth) when comparing it with larger-scale satellite and model data. Systematic differences between the in-situ measurements and the "true" soil moisture state (e.g., through miscalibration) cannot be resolved and might lead to an additional scaling of the error estimates. Besides, harmed assumptions in the triple collocation (e.g., too few data triplets or nongaussianity of the data sets) might additionally inflate the error estimate. Since many studies show that one single sensor might not be sufficient to represent larger-scale soil moisture, it is very likely that both external error sources dominate the overall error estimate and that the triple collocation result thus mainly reflects the spatial representativeness of the sensors as a function of the spatiotemporal variability of soil moisture. This cannot be proven globally because of the limited station density within the ISMN, leaving space for future studies to investigate the capabilities of the triple collocation method for the characterization of in-situ measurement quality.

A high variation in average error levels of particular networks and sensor types as well as in error variability within those was found. A global trend for decreasing errors with increasing measurement depth and for increasing errors with increasing average soil moisture conditions was observed, independent of the soil type and climate region. An interfering trend of decreasing errors with increasing average soil moisture conditions, which could only be partly explained with the spatio-temporal variability of soil moisture, is visible in data sets within temperate and cold regions without clear dry seasons, but less pronounced in clay and loam. Almost all sensors show lower errors when looking into anomalies instead of absolute soil moisture, which is mainly caused by the lower dynamic range of anomalies. A clear relationship between the dynamic range and 
error levels was also found for absolute soil moisture measurements. Moreover, 35.8\% of the insitu data sets exceed the current satellite mission accuracy requirement of $0.04 \mathrm{~m}^{3} \mathrm{~m}^{-3}$ in terms of the triple collocation error estimate for absolute soil moisture values. In-situ measurements are often considered as the "true" reference for this requirement, but also for a large variety of other applications and must therefore achieve significantly lower error levels. The limited spatial representativeness of single in-situ stations for larger-scale soil moisture levels and the limited knowledge about inherent sensor errors question the meaning of a single number for a direct comparison between in-situ sensors and satellite instruments. Almost all stations out of more than 1400 show considerable errors that should be taken into account in most applications, making the development of a standard procedure for a comprehensive quality assessment an essential task, including the development of procedures to reliably select representative existing or future sites for the in-situ - satellite inter-comparison.

This study investigated the results of the triple collocation, which is just one approach for estimating random errors and should be seen only complementary to other tools such as correlation, RMSD, and bias analysis or the assessment of spatial representativeness, since all these methods characterize different quality properties. The requirements on these properties highly vary with application and not a single sensor or site is capable to fulfil all of them. Detailed knowledge about the requirements of the particular application is crucial to support the comprehensive quality assessment by allowing the best possible selection of existing sites, but also by supporting the selection of representative locations and the best fitting sensor type for the setup of new sites. Finally, it helps to avoid misinterpretations of results based on in-situ data under the assumption that they are error-free. 


\section{Bibliography}

Albergel, C., C. Ruediger, T. Pellarin, J. Calvet, N. Fritz, F. Froissard, D. Suquia, A. Petitpa, B. Piguet, and E. Martin (2008), From near-surface to root-zone soil moisture using an exponential filter: an assessment of the method based on in-situ observations and model simulations., Hydrology and earth system sciences., 12(6), p. 1323-1337. 2

Albergel, C., C. Ruediger, D. Carrer, J.-C. Calvet, N. Fritz, V. Naeimi, Z. Bartalis, and S. Hasenauer (2009), An evaluation of ascat surface soil moisture products with in-situ observations in southwestern france, Hydrol. Earth Syst. Sci., 13(2), p. 115-124. 2

Albergel, C., P. de Rosnay, C. Gruhier, J. Munoz-Sabater, S. Hasenauer, L. Isaksen, Y. Kerr, and W. Wagner (2012), Evaluation of remotely sensed and modelled soil moisture products using global ground-based in situ observations, Remote Sensing of Environment, 118(o), p. 215-226, doi:10.1016/j.rse.2011.11.017. 1, 2, 3, 13, 20

Balsamo, G., F. Pappenberger, E. Dutra, P. Viterbo, and B. van den Hurk (2009), A revised land hydrology in the ecmwf model: a step towards daily water flux prediction in a fully-closed water cycle, Hydrol. Process., 25(7), p. 1046-1054. 17

Brocca, L., R. Morbidelli, F. Melone, and T. Moramarco (2007), Soil moisture spatial variability in experimental areas of central italy, Journal of Hydrology, 333, p. 356-373, doi:10.1016/j.jhydrol. 2006.09.004. 1, 2, 7

Brocca, L., F. Melone, T. Moramarco, and R. Morbidelli (2010a), Spatial-temporal variability of soil moisture and its estimation across scales, Water Resour. Res., 46(2), p. Wo2,516. 1, 2, 7

Brocca, L., F. Melone, T. Moramarco, W. Wagner, and S. Hasenauer (2010b), Ascat soil wetness index validation through in situ and modeled soil moisture data in central italy, Remote Sensing of Environment, 114(11), p. 2745-2755. 2

Brocca, L., S. Hasenauer, T. Lacava, F. Melone, T. Moramarco, W. Wagner, W. Dorigo, P. Matgen, J. Martinez-Fernandez, P. Llorens, J. Latron, C. Martin, and M. Bittelli (2011), Soil moisture estimation through ascat and amsr-e sensors: An intercomparison and validation study across europe, Remote Sensing of Environment, 115(12), p. 3390-3408. vii 
Brocca, L., T. Tullo, F. Melone, T. Moramarco, and R. Morbidelli (2012), Catchment scale soil moisture spatial-temporal variability, Journal of Hydrology, 422-423(o), p. 63-75. 1, 2, 7, 29

Cataldo, A., G. Cannazza, E. De Benedetto, L. Tarricone, and M. Cipressa (2009), Metrological assessment of tdr performance for moisture evaluation in granular materials, Measurement, 42(2), p. 254-263, doi:10.1016/j.measurement.2008.06.006. 3

Chauhan, N. S., S. Miller, and P. Ardanuy (2003), Spaceborne soil moisture estimation at high resolution: a microwave-optical/ir synergistic approach, International Journal of Remote Sensing, 24(22), p. 4599-4622, doi:10.1080/0143116031000156837. 1

Cosh, M. H., T. J. Jackson, P. Starks, and G. Heathman (2006), Temporal stability of surface soil moisture in the little washita river watershed and its applications in satellite soil moisture product validation, Journal of Hydrology, 323(1-4), p. 168-177. 2

Crow, W. T., A. A. Berg, M. H. Cosh, A. Loew, B. P. Mohanty, R. Panciera, P. de Rosnay, D. Ryu, and J. P. Walker (2012), Upscaling sparse ground-based soil moisture observations for the validation of coarse-resolution satellite soil moisture products, Rev. Geophys., 5o(2), p. RG2002. 2, 3, 6, 12

Dee, D. P., S. M. Uppala, A. J. Simmons, P. Berrisford, P. Poli, S. Kobayashi, U. Andrae, M. A. Balmaseda, G. Balsamo, P. Bauer, P. Bechtold, A. C. M. Beljaars, L. van de Berg, J. Bidlot, N. Bormann, C. Delsol, R. Dragani, M. Fuentes, A. J. Geer, L. Haimberger, S. B. Healy, H. Hersbach, E. V. Holm, L. Isaksen, P. Kallberg, M. Koehler, M. Matricardi, A. P. McNally, B. M. Monge-Sanz, J.-J. Morcrette, B.-K. Park, C. Peubey, P. de Rosnay, C. Tavolato, J.-N. Thepaut, and F. Vitart (2011), The era-interim reanalysis: configuration and performance of the data assimilation system, Q.J.R. Meteorol. Soc., 137(656), p. 553-597. 17

Dorigo, W., P. van Oevelen, W. Wagner, M. Drusch, S. Mecklenburg, A. Robock, and T. Jackson (2011a), A new international network for in situ soil moisture data, Eos Transactions AGU, 92 (17), p. $141-142.13$

Dorigo, W., A. Xaver, M. Vreugdenhil, A. Gruber, H. A, A. Sanchis-Dufau, D. Zamojski, C. Cordes, W. Wagner, and M. Drusch (2013), Global automated quality control of in situ soil moisture data from the international soil moisture network, Vadose Zone Journal, 12(3). 3, 21, 25

Dorigo, W. A., K. Scipal, R. M. Parinussa, Y. Y. Liu, W. Wagner, R. A. M. de Jeu, and V. Naeimi (2010), Error characterisation of global active and passive microwave soil moisture datasets, Hydrol. Earth Syst. Sci., 14(12), p. 2605-2616. 3, 4, 19, 20

Dorigo, W. A., W. Wagner, R. Hohensinn, S. Hahn, C. Paulik, A. Xaver, A. Gruber, M. Drusch, S. Mecklenburg, P. van Oevelen, A. Robock, and T. Jackson (2011b), The international soil moisture network: a data hosting facility for global in situ soil moisture measurements, Hydrol. Earth Syst. Sci., 15(5), p. 1675-1698. 13 
Entekhabi, D., E. Njoku, P. O’Neill, K. Kellogg, W. Crow, W. Edelstein, J. Entin, S. Goodman, T. Jackson, J. Johnson, J. Kimball, J. Piepmeier, R. Koster, N. Martin, K. McDonald, M. Moghaddam, S. Moran, R. Reichle, J. Shi, M. Spencer, S. Thurman, L. Tsang, and J. Van Zyl (2010), The soil moisture active passive (smap) mission, Proceedings of the IEEE, 98(5), p. 704716. 1

Famiglietti, J., J. Devereaux, C. Laymon, T. Tsegaye, P. Houser, T. Jackson, S. Graham, M. Rodell, and P. v. Oevelen (1999), Ground-based investigation of soil moisture variability within remote sensing footprints during the southern great plains 1997 (sgp97) hydrology experiment, Water Resources Management (1999), 35(6), p. 1839-1851. 2

Famiglietti, J. S., D. Ryu, A. A. Berg, M. Rodell, and T. J. Jackson (2008), Field observations of soil moisture variability across scales, Water Resour. Res., 44(1), p. Wo1,423. 2

Gruber, A., W. Dorigo, S. Zwieback, A. Xaver, and W. Wagner (2013), Characterizing coarse-scale representativeness of in situ soil moisture measurements from the international soil moisture network, Vadose Zone Journal, 12(2). vii, 1

Jackson, T., M. Cosh, R. Bindlish, P. Starks, D. Bosch, M. Seyfried, D. Goodrich, M. Moran, and J. Du (2010), Validation of advanced microwave scanning radiometer soil moisture products, Geoscience and Remote Sensing, IEEE Transactions on, 48(12), p. 4256-4272. viii, 2

Kerr, Y., P. Waldteufel, J.-P. Wigneron, S. Delwart, F. Cabot, J. Boutin, M. Escorihuela, J. Font, N. Reul, C. Gruhier, S. Juglea, M. Drinkwater, A. Hahne, M. Martin-Neira, and S. Mecklenburg (2010), The smos mission: New tool for monitoring key elements ofthe global water cycle, Proceedings of the IEEE, 98(5), p. 666-687. 1

Kumar, S. V., R. H. Reichle, K. W. Harrison, C. D. Peters-Lidard, S. Yatheendradas, and J. A. Santanello (2012), A comparison of methods for a priori bias correction in soil moisture data assimilation, Water Resour. Res., 48(3), p. Wo3,515. 2, 19

Liu, Y., W. Dorigo, R. Parinussa, R. de Jeu, W. Wagner, M. McCabe, J. Evans, and A. van Dijk (2012), Trend-preserving blending of passive and active microwave soil moisture retrievals, Remote Sensing of Environment, 123(0), p. 280-297, doi:10.1016/j.rse.2012.03.014. 13, 17

Liu, Y. Y., R. M. Parinussa, W. A. Dorigo, R. A. M. De Jeu, W. Wagner, A. I. J. M. van Dijk, M. F. McCabe, and J. P. Evans (2011), Developing an improved soil moisture dataset by blending passive and active microwave satellite-based retrievals, Hydrol. Earth Syst. Sci., 15(2), p. 425-436. 17, 19

Loew, A., and F. Schlenz (2011), A dynamic approach for evaluating coarse scale satellite soil moisture products, Hydrol. Earth Syst. Sci., 15(1), p. 75-90. 4 
Marczewski, W., J. Slominski, E. Slominska, B. Usowicz, J. Usowicz, S. Romanov, O. Maryskevych, J. Nastula, and J. Zawadzki (2010), Strategies for validating and directions for employing smos data, in the cal-val project swex (3275) for wetlands, Hydrol. Earth Syst. Sci. Discuss., 7(5), p. 70077057. vii

Martinez-Fernandez, J., and A. Ceballos (2003), Temporal stability of soil moisture in a large-field experiment in spain, Soil Sci. Soc. Am. J., 67(6), p. 1647-1656, doi:10.2136/sssaj2003.1647. 2

Martinez-Fernandez, J., and A. Ceballos (2005), Mean soil moisture estimation using temporal stability analysis, Journal of Hydrology, 312, p. 28-38. 2

Miralles, D. G., W. T. Crow, and M. H. Cosh (2010), Estimating spatial sampling errors in coarse-scale soil moisture estimates derived from point-scale observations, J. Hydrometeor, 11(6), p. 1423-1429, doi:10.1175/2010JHM1285.1. 2, 3, 4, 11

Mittelbach, H., F. Casini, I. Lehner, A. J. Teuling, and S. I. Seneviratne (2011), Soil moisture monitoring for climate research: Evaluation of a low-cost sensor in the framework of the swiss soil moisture experiment (swisssmex) campaign, J. Geophys. Res., 116(D5), p. Do5,111. 1, 14, 29

Mittelbach, H., I. Lehner, and S. I. Seneviratne (2012), Comparison of four soil moisture sensor types under field conditions in switzerland, Journal of Hydrology, 430-431(o), p. 39-49, doi:10. 1016/j.jhydrol.2012.01.041. 1, 3, 7, 14

Nachtergaele, F., and N. Batjes (2012), Harmonized world soil database, FAO. 18

Njoku, E., T. Jackson, V. Lakshmi, T. Chan, and S. Nghiem (2003), Soil moisture retrieval from amsr-e, Geoscience and Remote Sensing, IEEE Transactions on, 41(2), p. 215-229. 1

Pachepsky, Y. A., A. K. Guber, and D. Jacques (2005), Temporal persistence in vertical distributions of soil moisture contents, Soil Sci. Soc. Am. J., 69(2), p. 347-352, doi:10.2136/sssaj2005.0347. 2

Parrens, M., E. Zakharova, S. Lafont, J.-C. Calvet, Y. Kerr, W. Wagner, and J.-P. Wigneron (2011), Comparing soil moisture retrievals from smos and ascat over france, Hydrol. Earth Syst. Sci. Discuss., 8(5), p. 8565-8607. 1

Peel, M. C., B. L. Finlayson, and T. A. McMahon (2007), Updated world map of the koeppen-geiger climate classification, Hydrol. Earth Syst. Sci., 11(5), p. 1633-1644. 17

Plauborg, F., B. V. Iversen, and P. E. Larke (2005), In situ comparison of three dielectric soil moisture sensors in drip irrigated sandy soils, Vadose Zone Journal, 4(4), p. 1037-1047, doi:10.2136/vzj2004. o138. $1,3,14$

Reichle, R. H., and R. D. Koster (2004), Bias reduction in short records of satellite soil moisture, Geophys. Res. Lett., 31(19), p. L19,501. 2, 19 
Robinson, D. A., C. S. Campbell, J. W. Hopmans, B. K. Hornbuckle, S. B. Jones, R. Knight, F. Ogden, J. Selker, and O. Wendroth (2008), Soil moisture measurement for ecological and hydrological watershed-scale observatories: A review, Vadose Zone Journal, 7(1), p. 358-389, doi: 10.2136/vzj2007.0143. 1

Robock, A., K. Y. Vinnikov, G. Srinivasan, J. K. Entin, S. E. Hollinger, N. A. Speranskaya, S. Liu, and A. Namkhai (2000), The global soil moisture data bank, Bull. Amer. Meteor. Soc., 81(6), p. 12811299, doi:10.1175/1520-0477(2000)081<1281:TGSMDB>2.3.CO;2. vii

Schmugge, T. J. (1983), Remote sensing of soil moisture: Recent advances, Geoscience and Remote Sensing, IEEE Transactions on, GE-21(3), p. 336-344. 2

Scipal, K., T. Holmes, R. de Jeu, V. Naeimi, and W. Wagner (2008), A possible solution for the problem of estimating the error structure of global soil moisture data sets, Geophys. Res. Lett., 35(24), p. L24,403. 4

Starks, P. J., G. C. Heathman, T. J. Jackson, and M. H. Cosh (2006), Temporal stability of soil moisture profile, Journal of Hydrology, 324, p. 400-411. 2

Stoffelen, A. (1998), Toward the true near-surface wind speed: Error modeling and calibration using triple collocation, J. Geophys. Res., 103(C4), p. 7755-7766. 4, 11

Su, Z., J. Wen, L. Dente, R. van der Velde, L. Wang, Y. Ma, K. Yang, and Z. Hu (2011), The tibetan plateau observatory of plateau scale soil moisture and soil temperature (tibet-obs) for quantifying uncertainties in coarse resolution satellite and model products, Hydrol. Earth Syst. Sci., 15(7), p. 2303-2316. vii

Ulaby, F., M. M.K., and A. Fung (1982), Microwave remote sensing, active and passive: Radar remote sensing and surface scattering and emission theory., vol. II, Artech House Publishers. 17

Vachaud, G., A. Passerat De Silans, P. Balabanis, and M. Vauclin (1985), Temporal stability of spatially measured soil water probability density function, Soil Sci. Soc. Am. J., 49(4), p. 822-828, doi:10.2136/sssaj1985.03615995004900040006x. 2

Vereecken, H., S. Kollet, and C. Simmer (2010), Patterns in soil-vegetation-atmosphere systems: Monitoring, modeling, and data assimilation, Vadose Zone Journal, 9(4), p. 821-827, doi:10.2136/ vZj2010.0122. 1

Wagner, W., G. Lemoine, and H. Rott (1999), A method for estimating soil moisture from ers scatterometer and soil data, Remote Sensing of Environment, 7o(2), p. 191-207, doi:10.1016/ Soo34-4257(99)ooo36-X. 1, 2 
Walker, J. P., G. R. Willgoose, and J. D. Kalma (2004), In situ measurement of soil moisture: a comparison of techniques, Journal of Hydrology, 293, p. 85-99, doi:10.1016/j.jhydrol.2004.01.008. 1,14

Zwieback, S., K. Scipal, W. Dorigo, and W. Wagner (2012), Structural and statistical properties of the collocation technique for error characterization, Nonlin. Processes Geophys., 19(1), p. 69-80. $4,10,11,19$

Zwieback, S., W. Dorigo, and W. Wagner (2013), Estimation of the temporal autocorrelation structure by the collocation technique with emphasis on soil moisture studies, Hydrological Sciences Journal, in press. 4 